\title{
Targeted Disruption of Mouse Dip2B Leads to Abnormal Lung Development and Prenatal Lethality
}

\author{
Rajiv Kumar Sah ${ }^{1}$, Jun Ma ${ }^{2}$, Fatoumata Binta Bah ${ }^{1}$, Zhenkai Xing ${ }^{1}$, Salah Adlat ${ }^{1}{ }^{10}$, \\ Zin Ma Oo ${ }^{1}$, Yajun Wang ${ }^{1}$, Noor Bahadar ${ }^{1}$, Ameer Ali Bohio ${ }^{1}$, Farooq Hayel Nagi ${ }^{1}$, \\ Xuechao Feng ${ }^{1, *}$, Luqing Zhang ${ }^{1,3}$ and Yaowu Zheng $1, * \mathbb{C}$
}

1 Key Laboratory of Molecular Epigenetics, Institute of Genetics and Cytology, Northeast Normal University, Changchun 130024, China; kum235@nenu.edu.cn (R.K.S.); cissehbah@yahoo.fr (F.B.B.); xingzk444@nenu.edu.cn (Z.X.); land788@nenu.edu.cn (S.A.); zinmaroo23@yahoo.com (Z.M.O.); wangyj559@nenu.edu.cn (Y.W.); noorizever@yahoo.com (N.B.); gene_ali2016@hotmail.com (A.A.B.); haiy@nenu.edu.cn (F.H.N.); zhangluqing@gmail.com (L.Z.)

2 Wenzhou Institute, University of Chinese Academy of Sciences, Wenzhou 325001, China; junma@ciac.ac.cn

3 Cardiovascular Research Institute, University of California, San Francisco, CA 94158, USA

* Correspondence: fengxc997@nenu.edu.cn (X.F.); zhengyw442@nenu.edu.cn (Y.Z.)

Received: 23 September 2020; Accepted: 30 October 2020; Published: 3 November 2020

\begin{abstract}
Molecular and anatomical functions of mammalian Dip2 family members (Dip2A, Dip2B and Dip2C) during organogenesis are largely unknown. Here, we explored the indispensable role of Dip2B in mouse lung development. Using a LacZ reporter, we explored Dip2B expression during embryogenesis. This study shows that Dip2B expression is widely distributed in various neuronal, myocardial, endothelial, and epithelial cell types during embryogenesis. Target disruption of Dip $2 b$ leads to intrauterine growth restriction, defective lung formation and perinatal mortality. Dip2B is crucial for late lung maturation rather than early-branching morphogenesis. The morphological analysis shows that Dip $2 b$ loss leads to disrupted air sac formation, interstitium septation and increased cellularity. In BrdU incorporation assay, it is shown that Dip $2 b$ loss results in increased cell proliferation at the saccular stage of lung development. RNA-seq analysis reveals that 1431 genes are affected in Dip $2 b$ deficient lungs at E18.5 gestation age. Gene ontology analysis indicates cell cycle-related genes are upregulated and immune system related genes are downregulated. KEGG analysis identifies oxidative phosphorylation as the most overrepresented pathways along with the G2/M phase transition pathway. Loss of Dip2b de-represses the expression of alveolar type I and type II molecular markers. Altogether, the study demonstrates an important role of Dip2B in lung maturation and survival.
\end{abstract}

Keywords: Dip2b; LacZ expression; growth restriction; fetal lung development; prenatal lethality; RNA sequencing; mice

\section{Introduction}

There are three Disco-interacting protein 2 (DIP2) genes in mammals (Dip2a, Dip2b and Dip2c) and a single Dip2 gene in Drosophila melanogaster, Caenorhabditis elegans, bacteria, or single-cell eukaryotes. Dip2 genes are highly conserved from insects to humans but their biologic functions are still not clarified. Bioinformatic analysis of Dip2 homologs has suggested that DIP2 shares highly conserved domains of DNA methyltransferase-associated protein 1 (DMAP1), Acyl-coA synthetase (AMP-forming; Caic) and AMP-binding site 1 [1]. Dip2 was initially cloned and characterized in Drosophila and mouse using yeast two-hybrid techniques [2]. Since then, Dip2 protein has been extensively studied in Drosophila. Studies have shown that Drosophila Dip2 regulates bifurcation of mushroom body axons 
and directs axon projection under the regulation of c-Jun N-terminal kinase [3,4]. In Caenorhabditis elegans, Dip2 maintains neuron morphology and axon growth possibly through the AFD domain [5]. In mouse, DIP2 is highly expressed in the brain and may play a role in axon patterning in the central nervous system [2]. In mammals, Dip2A is the most studied family member and is a potential cell membrane receptor of Fslt1 [6]. Dip2A activation mediates Fstl1 protective effects against neuron and cardiac ischemia apoptosis [6,7]. Similarly, Dip2A/MGMT signaling is important for Fslt1 regulation in temozolomide resistance in glioblastoma [8]. Furthermore, blocking of the Fstl1-Dip2a axis improves anti-tumor immunity [9]. Dip2A knockout blocks acetylation of cortactin and leads to an autism-like phenotype [10]. Besides, Dip2a gene is a candidate for developmental dyslexia and autism [11,12].

In contrast to DIP2A protein, little work has been conducted on DIP2B and DIP2C. Dip2c gene has been implicated in development delay [13]. Loss of Dip2c initiates substantial DNA methylation and epithelial-mesenchymal transition in cancer cells [14]. DIP2B, a family member of DIP2 proteins coded by the Dip $2 b$ gene, is associated with the fragile site FRA12A on chromosome 12q13.1 in humans [15]. Exosomal transport of mir-133b-3p from mesenchyme to epithelium decreases expression of Dip2B protein and might act as an epigenetic regulator of genes responsible for $\mathrm{KIT}^{+}$progenitor expansion during organogenesis [16]. Defect in DIP2B was also discovered in several bioinformatics studies on disease models including schizophrenia, coronary artery disease (CAD), cervical squamous cell carcinoma, and colorectal cancer [17-20]. Although these bioinformatics analyses stated a potential intervention of Dip2B in physiopathological processes, the biological role of Dip2B is still far from clear.

The presence of three Dip2 genes in mammals with possibly distinctive and overlapping functions makes it a challenge to identify in vivo targets of individual DIP2 proteins and their roles in development. To extend the findings, we previously generated Dip2a knockout and Dip2a-LacZ knock-in mice via Crispr-Cas9 technology and showed that Dip2a is highly expressed in both neuronal and non-neuronal cell $[21,22]$. Disruption of Dip2a induced spine morphogenesis defect along with thin postsynaptic density and reduced synaptic transmission of pyramidal neurons [10]. Dip2A have a functional role in acetyl-coenzyme A (acetyl-CoA) synthesis [23]. We have also studied the transcriptome of E18.5 embryonic lung and brain under Dip2a regulation [24].

In the present study, we demonstrate the biological function of the Dip $2 b$ gene during embryonic lung development by utilizing a Dip $2 b^{\text {tm1a }}$ knock-in mouse model, which was originally generated by KOMP. In the current investigation, the expression pattern of the LacZ gene during embryogenesis was also examined, which is inserted in the Dip $2 b$ gene during the process of producing Dip $2 b$ deficient mice. Ablation of the Dip $2 b$ gene results in growth restriction, significant low birth weight and grossly normal development of offspring. These newborn mice die within a few hours after birth possibly due to obvious neonatal respiratory dysfunction. As for indicators of the adequacy of lung development, we compared Dip2 $b^{\text {tm1a/tm1a }}$ newborn with wild type littermates for the presence of respiratory distress, viability, and lung wet:dry ratio. We then performed anatomical and histological analysis of Dip2 $b^{\text {tm1a/tm1a }}$ lung from the early stages of embryonic development till birth. In late gestation (E18.5), we evaluated cell proliferation, cell death, collagen deposition, differentially expressed genes, and mRNA level of markers for alveolar and bronchiolar cell subtypes. Our findings depict the biological role of Dip $2 b$ in perinatal lung maturation and animal survival.

\section{Results}

\subsection{Dip2b Is Expressed in Multiple Organs during Development}

Dip $2 b$ transgenic mice containing the targeted Dip2 $b^{\text {tm1a(komp)wtsi }}$ locus (Dip2 $b^{\text {tm1a }}$ ) were generated by insertion of a targeted trap tm1a-knockout-first allele [25], in which a promoterless selection cassette was inserted into the seventh intron of the Dip $2 b$ allele consisting of an internal ribosome entry site (En2), splice acceptor (SA) site, and a $\beta$-galactosidase (LacZ) reporter fused in frame to a promoterless neomycin resistance marker (Figure 1A). The presence of a splice acceptor site allows LacZ-Neo cassette to become part of exon 7, and En2 warrants internal translational start of LacZ-Neo cassette. 
Tm1a locus genotyping was performed using primers Tm1a-F and Tm1a-R to give a mutant specific band of $300 \mathrm{bp}$. The wild type primers WT-F and WT-R amplify the intron 7 region and give a product of $350 \mathrm{bp}$ (Figure 1B).

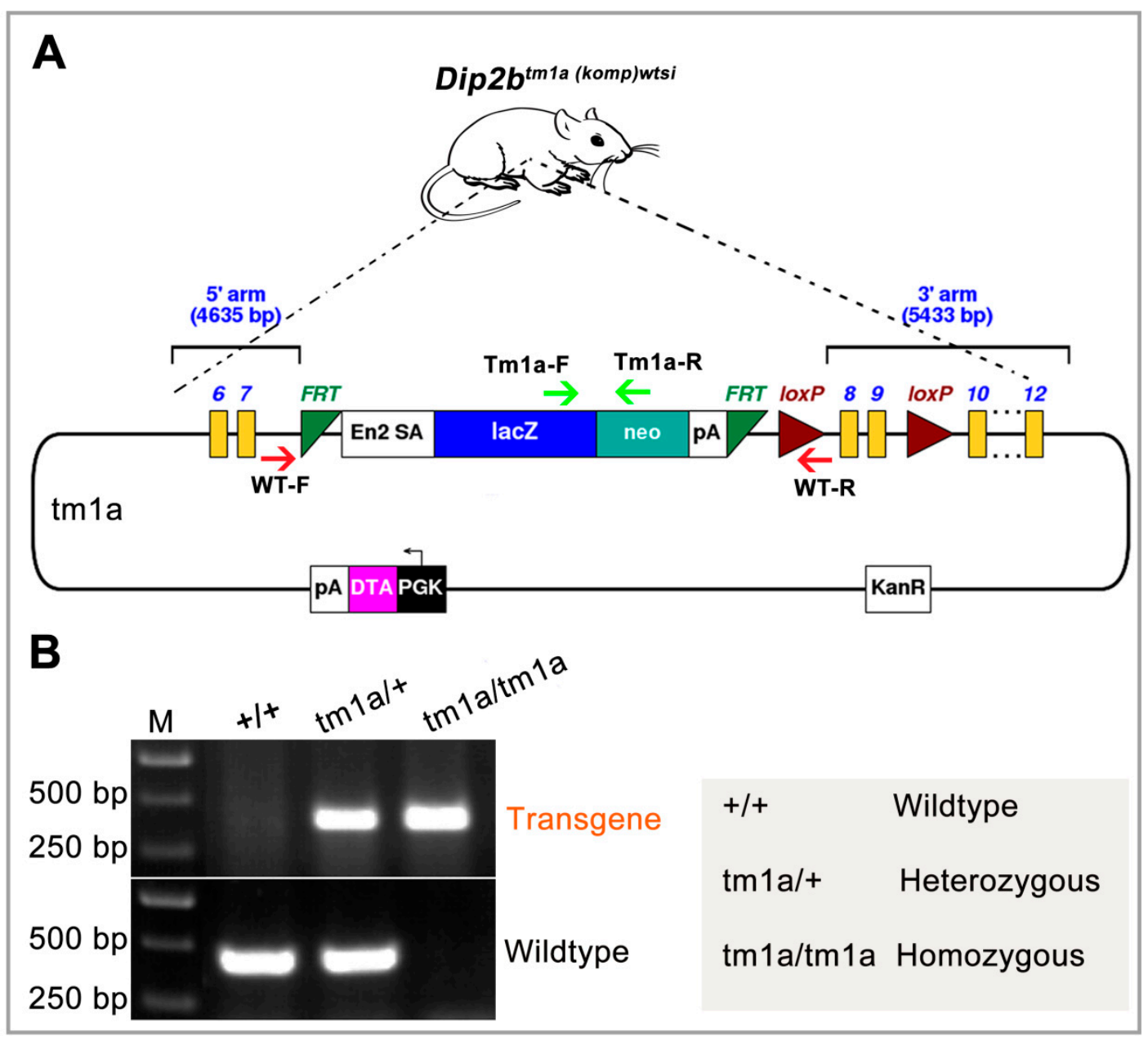

Figure 1. Structure of the Dip2 $b^{\text {tm1a }}$ (KOMP) Wtsi allele: (A) Exons 8 and 9 are flanked by loxp while FRT, lacZ, neo, and FRT elements are inserted in intron 7. En2 SA sequences will trans-splice lacZ to exon 7 and be frame matched. LacZ-Neo-pA is a cDNA coding a fusion protein for both galactosidase as reporter and NEO expression as positive selection marker. PGK-DTA-pA is a negative selection marker for gene targeting in ES cells. KanR is a bacterial selection marker; (B) Genotyping by PCR. A $300 \mathrm{bp}$ band appeared on gel for transgene allele and 350bp band for wild type allele. M, Molecular weight marker.

The expression of Dip $2 b$ during embryogenesis was analyzed by taking advantage of LacZ gene expression from the Dip $2 b$ locus. The $\beta$-galactosidase activity of the LacZ gene was analyzed by X-gal staining of embryos of Dip $2 b^{t m 1 a /+} \times D i p 2 b^{t m 1 a /+}$ mating. Gene expression was analyzed by qPCR as well. Dip $2 b$ mRNA was detected as early as in E6.5 embryos and increased from E8.5 thereafter.

Whole Mount LacZ staining of E9.5 revealed a strong expression of Dip $2 b$ throughout the embryos (Figure 2A). Staining was detected in the neural tissues including neuroepithelium surrounding optical and otic vesicles, branchial arch, auditory pit, and limb buds. Dip $2 b$ expression was also visualized in the ventral region of the developing brain and neural tube at this stage of development. At E11.5, the intensity of $\beta$-galactosidase staining in the telencephalon, anterior midbrain, hindbrain, spinal cord, somite, dorsal neural tube, and the buds of developing limb was strongly increased as compared to E9.5 (Figure 2B). At this stage, an expression domain in lung and heart was evident. At E12.5, the LacZ 
expression pattern was similar to that of E11.5 with strong expression in developing whisker follicles of the whisker pad (Figure 2C). WT littermate $(+/+)$ from all stages of development was devoid of the LacZ signal.

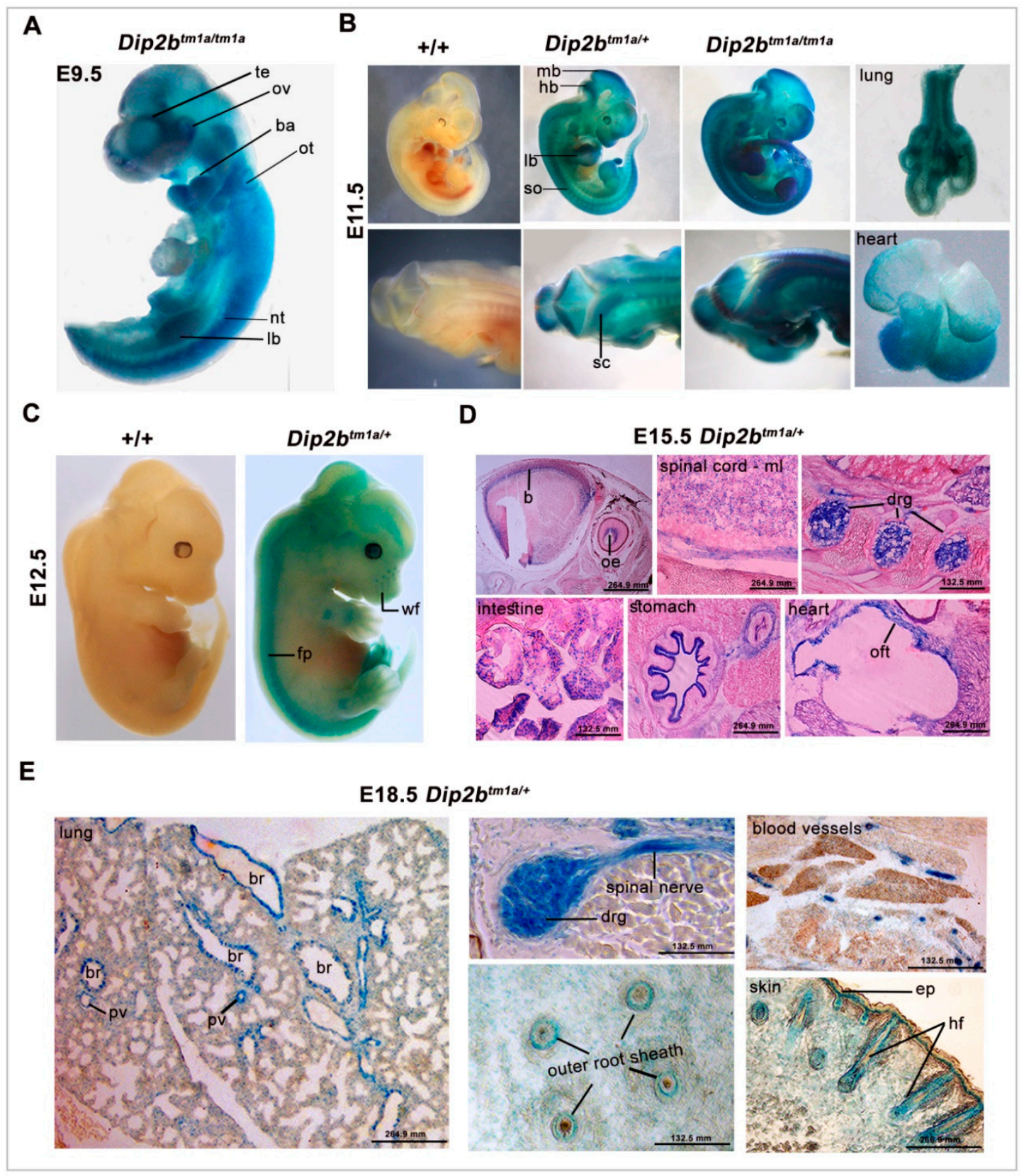

Figure 2. LacZ staining: (A) Whole mount of E9.5 Dip $2 b^{t m 1 a /+}$ mice reveals lacZ expression in brain and dorsal tissues. Staining is intense at telencephalon (te), optic vesicle (ov), branchial arch (ba), limb bud (lb), and neural tube (nt); (B) At E11.5, Dip2b expression is concentrated in brain (mid brian, mb and hind brain, hb), dorsal neural tube (dsnt), intersomitic regions (so) and spinal cord (sc). At this stage, signals in heart and lung are also evident; (C) At E12.5, LacZ staining expands towards dorsal region specifically in brain (b), floor plate (fp) and whisker follicles (wf). Wild type littermates were devoid of lacZ staining; (D,E) Transverse sections of E15.5 and E18.5 Dip2b $b^{\text {tm1a/+ }}$ embryos were stained for LacZ and counter-stained with eosin. LacZ signals are shown in various neural tissues, in epithelial and endothelial cells of variety of organs. Olfactory epithelium (oe), mantle layer (ml), outflow tract (oft), blood vessels (bv), bronchus \& bronchiole (br), pulmonary vessels (pv), epidermis (ep), and hair follicles (hf). 
Staining of E15.5 and E18.5 embryo sections $(18 \mu \mathrm{m})$ showed stronger and new expression domains compared to the early-stage embryos (Figure 2D,E). Expression was evenly distributed in the developing nervous system including the brain, spinal cord mantle layer, spinal nerves, and dorsal root ganglion. In heart sections, staining was located in the epicardium and outflow tract. Similarly, Dip $2 b$ was strongly expressed in epithelial-derived tissues, including intestine pseudostratified epithelium, stomach and skin epidermis, and hair follicles. In the lungs, Dip $2 b$ was expressed selectively in the respiratory epithelium lining of the intrapulmonary bronchus and bronchiolar duct. Staining of E18.5 frozen sections revealed that new domains of expression in the vascular systems are seen as in pulmonary vessels.

\subsection{Dip2b Knockout Leads to Fetal Growth Restriction, Birth Weight Reduction and Perinatal Lethality}

Observation of newborn pups from Dip $2 b$ heterozygous intercrosses demonstrated the lethality of homozygous Dip $2 b^{\text {tm1a }}$ mice. From genotyping of 316 live pups from 36 litters, no Dip $2 b^{\text {tm1a }}$ homozygotes survive to postnatal day 2 (Table 1). Further examination of 443 embryos of different prenatal stages (E9.5-18.5) showed expected Mendelian segregation of Dip2b genotype distributions. Hence, it is evident that Dip2b null mice survived embryonic stages but died after birth. To better estimate the time point of lethality, Dip $2 b^{t m 1 a /+}$ intercross cages were kept on close observation for deliveries and deaths. Among the newborns, all the homozygotes died within $4-5 \mathrm{~h}$ after birth (Figure 3A). In summary, the Dip2b-tm1a allele is associated with postnatal lethality and all the homozygous fail to survive beyond $\mathrm{p} 1$.

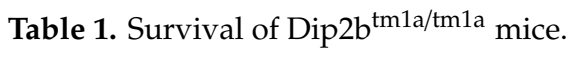

\begin{tabular}{cccccc}
\hline Age & $+/+$ & Dip $\boldsymbol{b}^{\text {tm1a/+}}$ & Dip $^{\text {tm1 }} \boldsymbol{b}^{\text {tm1 } 1 \boldsymbol{a}}$ & $\boldsymbol{\chi}^{\mathbf{2}}$ 10df & $\boldsymbol{p}$ Value \\
\hline E9.5 & $7(23.3 \%)$ & $15(50.0 \%)$ & $8(26.6 \%)$ & 0.81 & 0.26 \\
E11.5 & $12(23.5)$ & $25(49.0 \%)$ & $14(27.5 \%)$ & 0.71 & 0.99 \\
E12.5 & $22(25.5 \%)$ & $40(46.5 \%)$ & $24(27.9 \%)$ & 0.56 & 0.14 \\
E15.5 & $25(24.5 \%)$ & $48(47.0 \%)$ & $29(28.5)$ & 0.37 & 0.26 \\
E18.5 & $46(26.2 \%)$ & $90(51.4 \%)$ & $39(22.2 \%)$ & 0.35 & 0.71 \\
P1 & $102(32.2)$ & $214(67.8 \%)$ & $0(0 \%)$ & 0.61 & 0 \\
Expected & $25 \%$ & $50 \%$ & $25 \%$ & &
\end{tabular}

$\chi 2$ analysis progeny of Dip2 $b^{\text {tm1a/+ }} \times$ Dip2 $b^{\text {tm1a/+ }}$ timed mating's with 6 degrees of freedom. Percentage of observed embryos is presented in parenthesis. $p$ is the statistical significance value.

To further characterize the developmental timeline of $\operatorname{Dip} 2 b$ mutant, litters derived from crosses of Dip $2 b^{t m 1 a /+}$ heterozygous mice were examined at embryonic day (E) 11.5, E12.5, E13.5, E15.5, E18.5, and E19.5 (P0). No gross morphological defects were identified in Dip2 $b^{\text {tm1a/tm1a }}$ embryos from E11.5 to E18.5. However, Dip $2 b$ homozygous embryos were comparatively smaller than wild type or heterozygous littermates (Figure 3B). Starting at E15.5, the Dip $2 b^{\text {tm1a/tm1a }}$ mutant embryos showed a significant reduction in weight as compared to the weight of wild type or Dip $2 b^{\text {tmla/+ }}$ embryos (Figure 3C). 

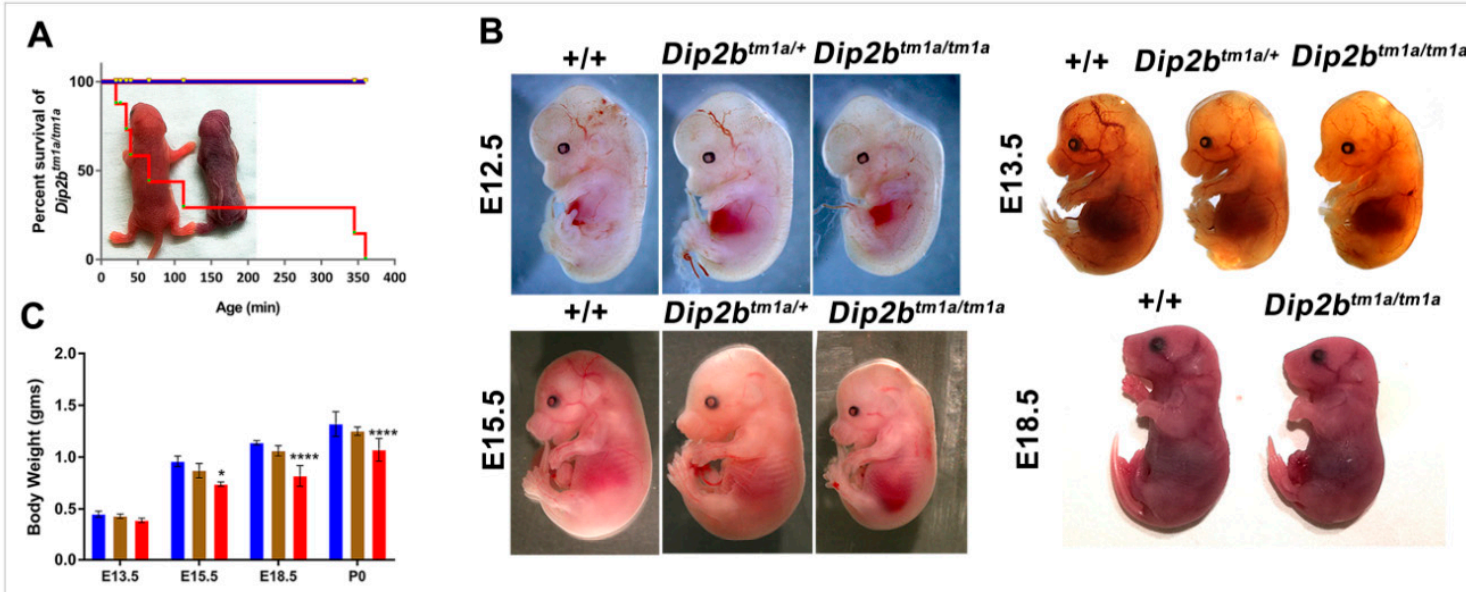

D

\section{E}

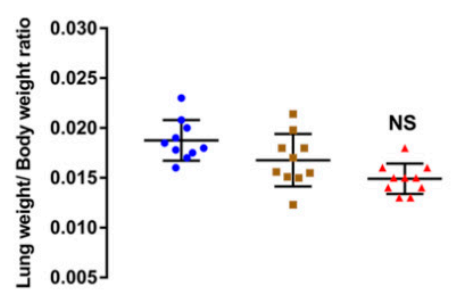

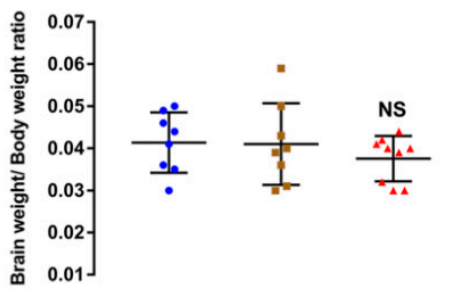

$\mathbf{F}$

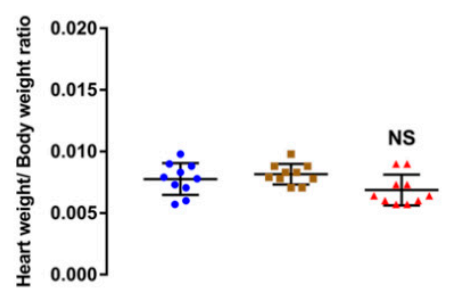

+ +/+ Dip2b

Figure 3. Phenotypical analysis: (A) Perinatal lethality in Dip2 $2 b^{\text {tm1a/tm1a }}$ mice. Survival plot show significant lethality of Dip2 $b^{\text {tm1a/tm1a }}$ mice at P0 $(p<0.0001, n=36)$. Background picture shows cyanosis immediately after birth; (B) Representative images of newborns; (C) Body weight at E13.5-P0; (D-F) Average weights (in grams) of brain, lung and heart at E18.5. Wet weights of organs were normalized to total body weight. ${ }^{*} p<0.05,{ }^{* * * *} p<0.0001$. NS, not significant.

\subsection{Dip2b Inactivation Causes Respiratory Distress and Pathologic Lung Development}

Direct observation of litters from Dip $2 b^{\text {tm1a/+ }}$ intercross revealed cyanosis in Dip $2 b$ homozygotes (Figure 3A), suggesting a lack of proper oxygenation due to circulatory or respiratory dysfunction. Dip2 $b^{\text {tm1a/tm1a }}$ pups exhibited difficulty in breathing, characterized by a gasping mouth and exaggerated diaphragmatic contraction (Video S1). Therefore, lungs from wild type and Dip2 $b^{\text {tm1a/tm1a }}$ were first investigated for architectural problems. Macroscopic examination showed that the gross morphology, the number of lobes, lung shape, and lung/body weight ratio were similar between Dip $2 b^{\text {tm1a/tm1a }}$ and wild type mice at P0 (Figure 3D). No significant difference in the ratio of brain/body and heart/body weight between Dip2 $b^{\text {tm1a/tm1a }}$ and wild type further confirmed that Dip2 $b^{\text {tm1a/tm1a }}$ developed normally (Figure 3E,F). When intact lungs including trachea were placed in PBS and observed for flotation, lungs from wild type floated but Dip $2 b^{t m 1 a / t m 1 a}$ sank, representing inadequate aeration (Figure 4A). It is clear that Dip2 $b^{\text {tm1a/tm1a }}$ mice failed to fully inflate their lungs. Histology studies at P0 show that while wild type lung exhibited normal lung structure with inflated and expanded alveolar space, Dip $2 b^{\text {tm1a/tm1a }}$ lungs displayed reduced alveolar sacs formation and unexpanded intra-alveolar septation. In more severe cases, Dip $2 b^{\text {tm1a/tm1a }}$ lungs showed collapsed air sac formation with dense cellularity (Figure 4B,C). Based upon these phenotypic characterizations, we suspect that abnormal lung maturation is probably the primary cause of respiratory distress and death of Dip2 $b^{\text {tm1a/tm1a }}$ neonates. 


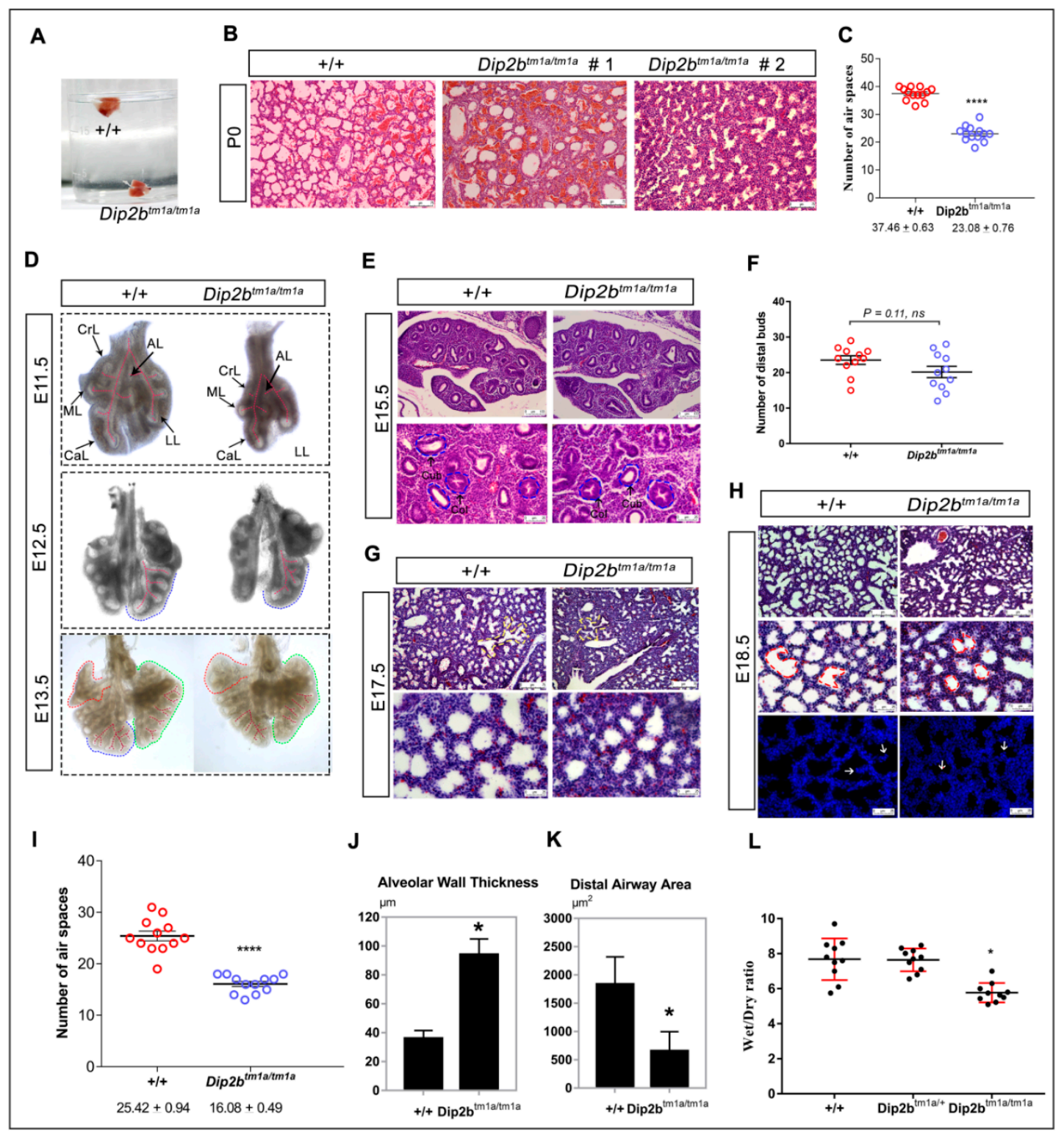

Figure 4. Lung structure comparison of WT and Dip2 $b^{\text {tm1a/tm1a }}$ littermates: (A) Phenotype of a postnatal day 0 (P0) lungs after birth. The P0 lung was examined while it was floating in PBS; (B) The morphology of lung tissue and alveoli air space in WT and Dip2 $b^{\text {tm1a/tm1a }}$ at P0. H\&E-stained (Scale bar, $75 \mu \mathrm{m}$ )

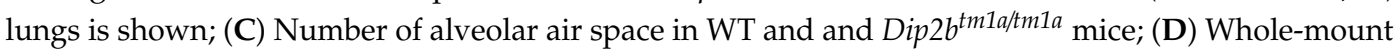
of E11.5-E13.5 lungs of Dip2 $b^{\text {tm1a/tm1a }}$ (left) and wild-type (right) mice. CrL, right cranial lobe; $\mathrm{ML}$, right medial lobe; CaL, right caudal lobe; AL, right accessory lobe; LL, left lobe; (E) The morphology of lung tissue in WT and Dip2b $b^{t m 1 a / t m 1 a}$ at E15.5. H\&E-stained (Scale bar, $100 \mu \mathrm{m}$ and $25 \mu \mathrm{m}$ ) lungs is shown. Col, columnar epithelium; Cub, cuboidal epithelium; (F) Quantification of distal epithelial buds in E15.5 lungs; $(\mathbf{G}, \mathbf{H})$ The morphology of lung tissue in WT and Dip2b $b^{\text {tm1a/tm1a }}$ at E17.5 and E18.5 is shown. Alveolar septation is shown by white arrow. H\&E and DAPI stained (Scale bar, $75 \mu \mathrm{m}$ and $25 \mu \mathrm{m}$ ) lungs are shown; (I-K) Number of alveolar spaces, size and thickness in WT and Dip2 $b^{\text {tm1a/tm1a }}$ mice at E18.5; (L) Wet/dry ratio of E18.5 lung tissues. Data are means $\pm \operatorname{SD}\left(n=3,{ }^{*} p<0.5,{ }^{* * * *} p<0.0001\right.$ and NS: $p=0.11$ ) calculated by standard two-tailed unpaired $t$-test.

Anatomical and histological analysis of lungs at P0 suggested that homozygous Dip $2 b^{\text {tm1a/tm1a }}$ mice were born with poor lung morphology. To investigate at what stage lung defects were first evident, we examined lungs from early developmental stages starting from branching morphogenesis to the saccular formation (E11.5-18.5). At E13.5, five lobes of right and left lungs were clearly distinguishable 
in both wild type and Dip2 $b^{\text {tm1a/tm1a }}$ embryos. It was evident that Dip2 $b^{\text {tm1a/tm1a }}$ lungs are comparatively smaller. Development of primitive bronchi that separate the lungs and development of epithelial buds that give rise to five lobes were visible but with a tendency to form less well-defined secondary and tertiary branches, as the pulmonary tree branching was extensive in wild type (Figure 4D). At E15.5, microscopically distinct columnar or cuboidal epithelium, correlating to the pseudo glandular period of lung development, is evident in both wild type and Dip2b $b^{\text {tm1a/tm1a }}$ (Figure 4E). Although the total number of distal epithelial buds in Dip2 $b^{\text {tm1a/tm1a }}$ lungs $(20.18 \pm 1.6, n=11)$ was comparatively less than wild type lungs $(23.55 \pm 1.2, n=11)$, the observed difference was not statistically significant (Figure 4F).

During the late canalicular stage of lung development at E17.5, wild type lungs displayed narrower terminal buds as expected. In contrast, Dip $2 b^{\text {tm1a/tm1a }}$ lung had dense appearance, few distal saccular expansion and bronchus diversion (Figure 4G). At E18.5, wild type lung had many small sacs with thin septa, but in Dip2 $b^{\text {tm1a/tm1a }}$ lung had markedly delayed septation (Figure $4 \mathrm{H}$ ). In addition, the wild type lungs were highly branched and the wall of the saccules has multiple short buds that elongate to form secondary septa, whereas in Dip2 $b^{\text {tm1a/tm1a }}$ lung, the buds were either short or completely absent. A quantitative analysis showed that on average, Dip $2 b^{\text {tm1a/tm1a }}$ lungs had a small number of distal air sacs and increased thickness of alveolar wall in comparison to wild type lung at E18.5 (Figure 4I-K). In addition, Lung wet/dry ratio showed a reduced amount of lung fluid in Dip2 $b^{\text {tm1a/tm1a }}$ as compared with wild type, presumably leading to the smaller alveolar space observed (Figure $4 \mathrm{~L}$ ). In particular, Dip2 $b^{\text {tm1a/tm1a }}$ lung at E18.5 and P0 showed increased cellularity and reduced terminal air sacs formation. No other histological abnormalities in proximal airway epithelial, smooth muscle, or bronchial epithelial were observed from Dip2 $b^{\text {tm1a/tm1a }}$ mice when compared between wild type. In addition, Sirius red staining did not show any significant differences in collagen deposition between wild type and Dip2b $b^{t m 1 a / t m 1 a}$ at E18.5 (Figure S1). These results indicate that Dip2B is important for lung organogenesis and saccular stage lung development.

\subsection{Dip2b Regulates Cell Proliferation but Not Apoptosis in Lungs}

To evaluate if there was overall cell loss (Hypoplasia) in the lungs of Dip2 $b^{\text {tm1a/tm1a }}$ mice, the left lung DNA content of the E18.5 embryo was accessed. While the bodyweight of Dip2 $b^{\text {tm1a/tm1a }}$ was less than the wild type, there was a substantial increase in the total DNA in the mutant lung compared to wild type and heterozygous, with an increased ratio of DNA content to body weight (Table 2). Thus, while differentiation of type I and type II cells appears defective in the Dip2 $b^{\text {tm1a/tm1a }}$ lungs (Figure 4, there is an apparent increase in cell number in the Dip2 $b^{\text {tm1a/tm1a }}$ lungs, suggesting Dip2B may be involved in cell proliferation or apoptosis during lung maturation [26].

Table 2. Body weight and DNA contents of the left lung.

\begin{tabular}{cccc}
\hline Genotype & No. of Pups & Average Body wt $(\mathrm{g})$ & Left Lung DNA/Total Body wt $(\boldsymbol{\mu g} / \mathrm{g})$ \\
\hline$+/+$ & 7 & $1.14 \pm 0.027$ & $43.6 \pm 3.93$ \\
Dip $2 \boldsymbol{b}^{\text {tm1a/+ }}$ & 13 & $1.06 \pm 0.050$ & $52.9 \pm 5.08$ \\
Dip $2 \boldsymbol{b}^{\text {tm1a/tm1a}}$ & 6 & $0.82 \pm 0.108$ & $63.1 \pm 6.47$ \\
\hline
\end{tabular}

Data are means \pm standard deviation.

To evaluate if cell proliferation was altered, E15.5 and E18.5 pregnant dams were injected with 5-bromo-2-deoxyuridine (BrdU). Dip2 $b^{\text {tm1a/tm1a }}$ lungs at E18.5 showed a significant increase in BrdU positive cell compared to wild type lungs $(1350 \pm 10.82$ versus $1102 \pm 16.51, n=14, p<0.0001$, Figure 5B), indicating that a higher level of cell proliferation has occurred in the Dip2 $b^{\text {tm1a/tm1a }}$ lungs. This apparent increase in proliferation is consistent with the thickened mesenchyme and increased DNA content in Dip2 $b^{\text {tm1a/tm1a }}$ lungs and may reflect a failure of the normal reduction in mesenchymal proliferation seen during lung maturation [26]. There was no difference in BrdU incorporation at E15.5 between Dip2 $b^{\text {tm1a/tm1a }}$ and wild type $(966.6 \pm 13.81, n=12$ versus $957.6 \pm 15.45, n=0, p=0.66$; Figure $5 \mathrm{~A}$ ), suggesting that cell proliferation was intact at the branching stage but interrupted during 
the saccular stage and that defective proliferation is coupled to the maturation defect. Cell apoptosis was measured by terminal deoxynucleotidyl transferase dUTP nick-end labeling (TUNEL) assay. At E18.5, a comparable number of TUNEL positive cells were detected in both groups (1116 \pm 19.7 versus $1102 \pm 20.49, n=15, p=0.61$, Figure S2).

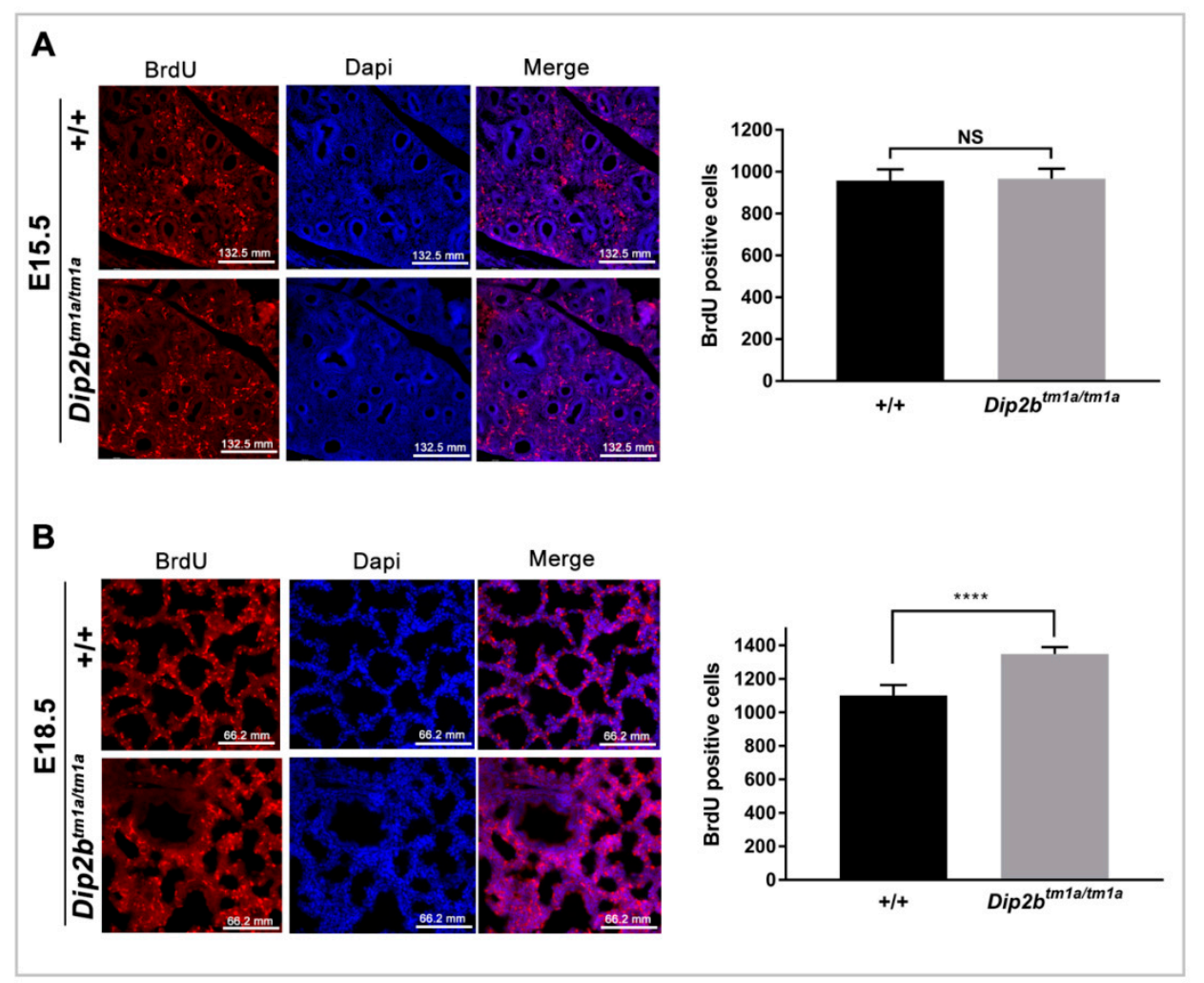

Figure 5. Cell proliferation assay by Bromodeoxyuridine (BrdU) incorporation in lungs: (A) BrdU-Positive cell number in E15.5 lungs. Scale bars, $132.5 \mu \mathrm{m}$; (B) Cell proliferation assay at E18.5. Scale bars, $66.2 \mu \mathrm{m}$. NS $=$ not significant, ${ }^{* * * *} p<0.0001$ by student's $t$-test. Three pubs were analyzed per group.

\subsection{Dip2b Regulates Expression of Cell Cycle Genes, Epithelial Cell Differentiation Markers and Lung Mediators}

To further examine whether the loss of Dip $2 b$ alters lung gene expression profiles, we performed RNA sequencing of E18.5 lungs (Table S1). The study found 1431 genes differentially expressed (Fold change $\geq 2$, FDR $<0.01$ ), comprising 696 up and 735 downregulated in Dip2b $b^{\text {tm1a/tm1a }}$ lungs (Figure 6A and Table S2).

Gene Ontology (GO) analysis was performed on these differentially expressed genes (DEGs) by separating upregulated from downregulated genes to isolate particular biological processes that may explain the distinct phenotype observed in E18.5 Dip2 $b^{\text {tm1a/tm1a }}$ lungs. The top 10 enrichment terms for up and downregulated genes are listed in Figure 6B,C. Results show that 94 up-regulated genes are highly overrepresented under GO term cell cycle, including several cell division cycle (Cdc20, Cdc45, Cdc6, Cdc7, Cdca2, Cdca3, Cdca5, and Cdca8), cyclin (Ccna2, Ccnb1, Ccnb2, Ccne1, and Ccnf) and kinesin (Kif11, Kif18b, Kif20b, Kif23 and Kif2c) family member genes, all of which have well-established functions in cell cycle control (Table S3). The enrichment of cell proliferation was observed at E18.5 Dip $2 b$ lungs. Among GO terms from downregulated genes, 54 genes annotated under the immune system process are highly overrepresented (Table S3). The mRNA levels of these DEGs from the cell cycle and immune system process are confirmed by quantitative real-time PCR (QPCR) (Figure 6D,E). These results suggest Dip2B downregulates the cell cycle and upregulates the immune system during lung development. 
A

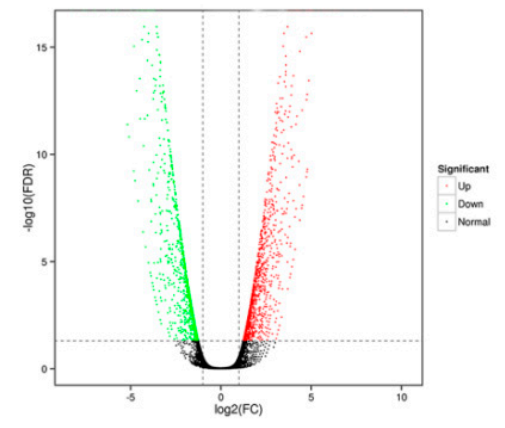

C

Biological Process - Down Regulated Genes

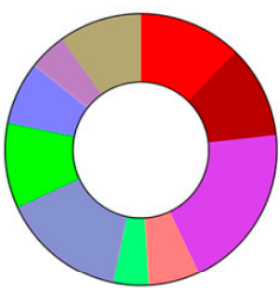

$\mathbf{F}$

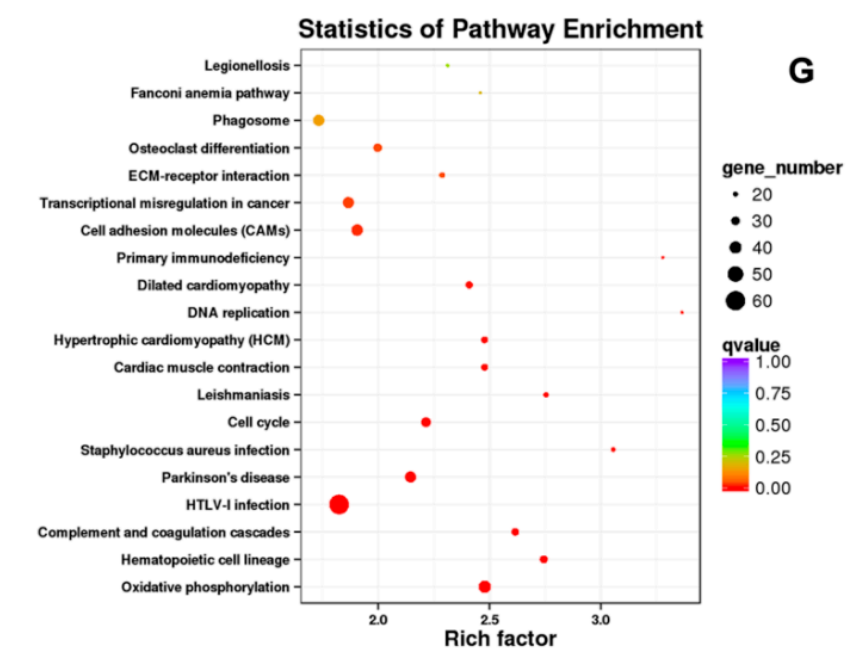

B Biological Process - Up Regulated Genes

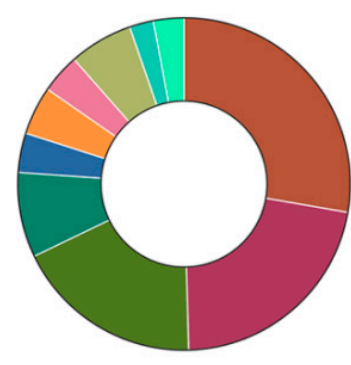

Cell cycle, $8.70 \mathrm{E}-36$

$\square$ Cell division, 1.70E-35

Mitotic nuclear division, 7.70E-33

Chromosome segregation, $4.80 \mathrm{E}-19$

Mitotic sister chromatid segregation, 1.60E-12

$\square$ Cardiac muscle contraction, 2.30E-11

Sarcomere organization, $1.30 \mathrm{E}-10$

$\square$ DNA replication, 4.30E-09

$\square$ Cardiac myofibril assembly, 3.00E-08

$\square$ Mitotic cytokinesis, 3.70E-07

D

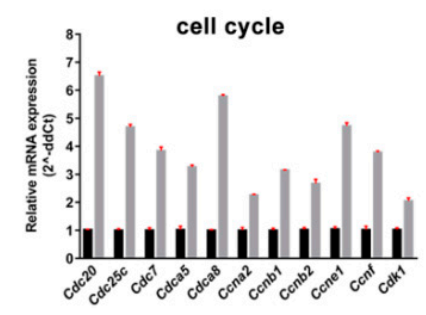

E

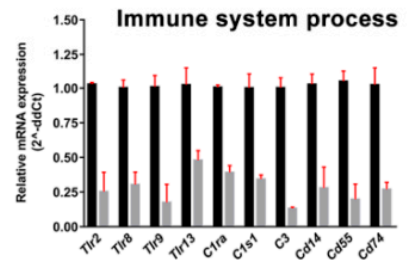

Figure 6. E18.5 Lung transcriptome analysis defined by FDR $<0.01$ and Fold change $>2$ : (A) Volcano plots of differentially expressed genes (DEGs). The red and green dots represent up-regulated and downregulated genes respectively; (B-E) Gene ontology (GO) analysis of DEGs; (B,C) Pie charts of top 10 overrepresented biological process terms from upregulated and downregulated genes respectively; (D,E) The mRNA expression levels of 11 \& 10 genes annotated under biological process term 'Cell cycle' and 'immune system process' determined by qPCR. The red error bars represents standard deviation; (F,G) Pathway enrichment analysis; (F) KEGG pathway enrichment scatter plot. Each circle represents a KEGG pathway. The $Y$-axis represents the name of the pathway and the $X$-axis indicates Enrichment Factor, indicating the proportion of the annotated genes in the pathway. The lowest $Q$ value represents the most significant pathway; (G) Biocarta G2/M phase transition pathway. A total of seven DEGs were annotated. Red arrow represents upregulated genes while green arrow represents downregulated genes. 
To analyze whether these genes are over-presented on a pathway, KEGG analysis was performed. KEGG pathway analysis identified that oxidative phosphorylation and hematopoietic cell lineage pathways are significantly enriched in Dip2 $b^{\text {tm1a/tm1a }}$ lungs (Figure 6F). Under the oxidative phosphorylation pathway, ATPase, NADH ubiquinone oxidoreductase, and cytochrome c oxidase family genes were upregulated, whereas mitochondria-encoded NADH ubiquinone oxidoreductase and ATP synthase membrane family genes were downregulated (Table S4). Similarly, genes annotated under hematopoietic cell lineage are mostly downregulated CD markers (Table S4). Biocarta pathway analysis shows a significant hit particularly on the G2/M phase transition pathway (Figure 6G). The decreased expression of cell cycle inhibitor Cdkn1a and increased expression of Ccnb1, Cdc25c, Chek1, Plk1, Cdkn2d, and Brca1 may have increased BrdU-positive cells in E18.5 Dip2b bla/tm1a $^{\text {th }}$ lungs. These results indicate that Dip2B may regulate lung development through altering oxidative phosphorylation, hematopoietic cell lineage, and G2/M transition pathways.

Lung morphogenesis at late gestation is characterized by a dramatic increase in epithelial cell differentiation markers [27]. To determine whether lung immaturity corresponds to reduced expression of these markers, we searched all the known markers related to alveolar and bronchial epithelial cell lineages in RNA sequencing data [28] and validated these markers by qPCR (Figure 7). Dip2b ${ }^{\text {tm1a/tm1a }}$ lung showed reduced transcripts of surfactant-secreting cuboidal alveolar type 2 (AT2) cell markers including Sftpa1, Sftpb, Sftpd, Cxc115, Lyz1, Lyz2, Muc1, S100g, and Scd1, as well as flat alveolar type 1 (AT1) cell markers specialized for gas exchange including Aqp5, Timp3, Col4a3, and Scnn1g. Also, markers for Clara cell comprising Scgb1a1, Chad, Nupr1, Osgin1, C3, Bcl6, and Tacstd2 were also downregulated except for Itm2a, Krt15, which were upregulated. In contrast, markers of the ciliated cells including Ccdc67, Ncs1 and Mif1 were upregulated. Extracellular matrix and Growth factors mediate tissue interactions and regulate a variety of cellular functions that are critical for normal lung development and homeostasis [29,30]. In our study, we find several ECM like Col4a3, Col4a4, Itga8, Itgb2, Itgb3, Itgax, Mmp19, mmp8, and Mmp9 and growth factors like Tgfb family, Bmp family and Wnt family genes were de-regulated (Figure 7E,F). These results indicate that Dip2B regulates expression of terminal differentiation markers of Type1, Type 2 and markers of the ciliated cell along with ECM and growth factors critical for terminal lung development. 
A

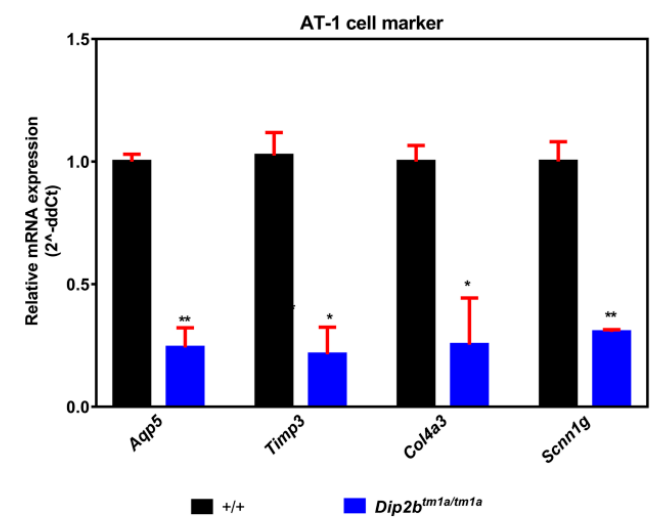

C

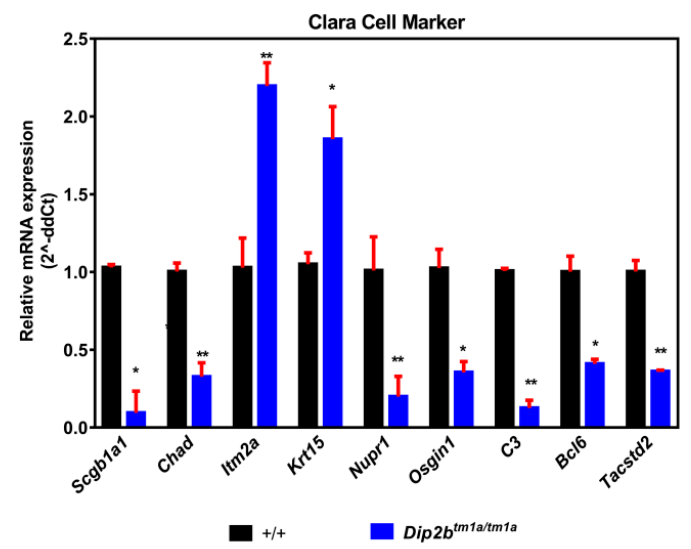

$\mathbf{E}$

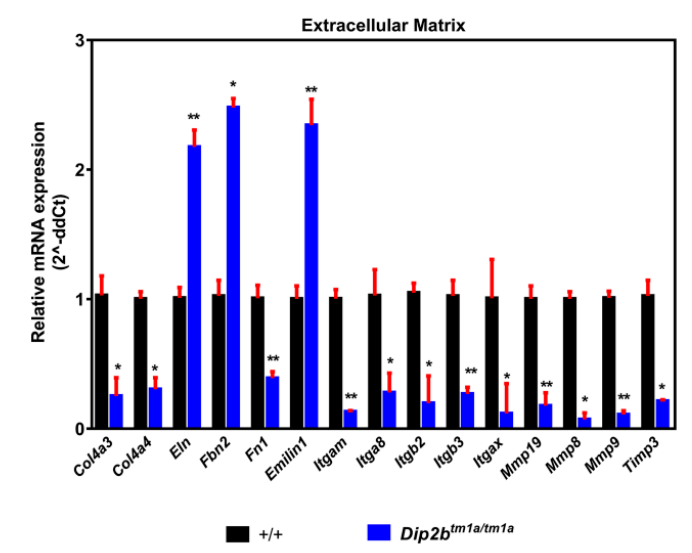

B

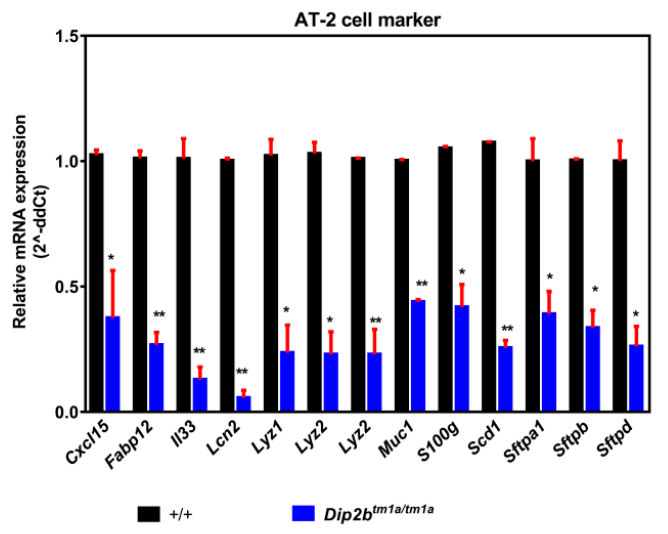

D

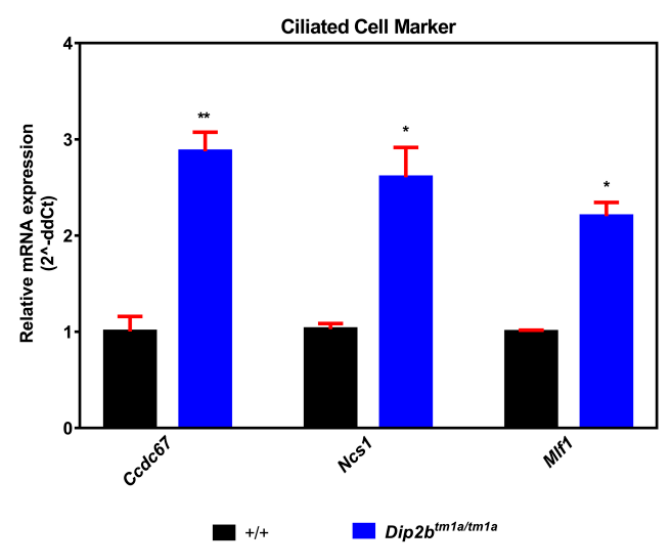

$\mathbf{F}$

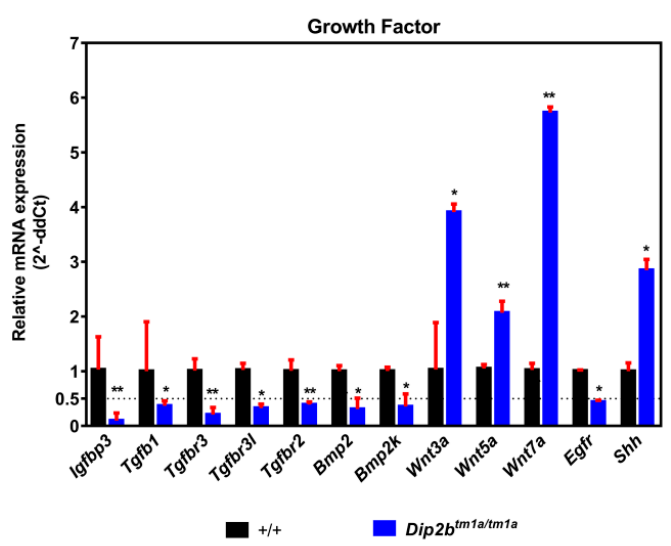

Figure 7. (A-F) Gene expression analysis of alveolar, bronchiolar cell markers and lung mediator genes by qPCR of E18.5 lungs. Mix of total RNAs from three pups were analyzed per group. Data are means $\pm \mathrm{SD}\left(n=3,{ }^{*} p<0.05\right.$ and $\left.* * 0.001\right)$.

\section{Discussion}

In the present study, the functional roles of Dip2B were investigated using Dip2 $b^{\text {tm1a/tm1a }}$ mice. Dip $2 b^{\text {tm1a/tm1a }}$ mice are conditional null and LacZ reporter also generated by KOMP using tm1a knockout first strategy [25]. We have used heterozygous Dip $2 b^{t m 1 a /+}$ for expression study and homozygous Dip $2 b^{\text {tm1a/tm1a }}$ mice for functional analysis. Abundant LacZ expression has been found in most analyzed organs starting from the early stages of development and mapped to distinct cell types or individual 
cells. The prominent sites of expression were various neuronal, myocardial, endothelial, and epithelial cell types, indicating the potential biological role of Dip2B in these specific cells. The observed LacZ expression pattern partially overlaps with Dip2A, which is an indication of potential compensation roles in these tissues [22]. Mapping Dip2B expression patterns in embryonic tissue are of particular interest, since, until now, validation of in situ Dip2B expression analysis in mouse embryo has not yet been available. Also, the transcriptional mechanism behind the normal constitutive or cell-type-specific expression of Dip2b remains unknown. Dip $2 b^{\text {tm1a }}$ mouse model provides a perfect tool to study Dip2B-regulated genes and pathways.

Despite over 15 years of history, the physiological role of the Dip $2 b$ gene in mammals is still poorly understood. In recent years, DIP2B has drawn increased attention for its potential role in neurocognitive disorder $[15,17]$. However, there has been no evidence either from tissue culture or animal models that show a contribution of Dip2B in organogenesis. In this study, we have discovered that mouse homozygous inactivation of Dip2B exerts intrauterine growth restriction and death of newborns within a few hours due to abnormal lung pathology and neonatal respiratory distress (NRD). Dip $2 b^{\text {tm1a/tm1a }}$ mutants showed the apparent arrest of fetal lung maturation at the saccular and late canalicular stage as evidenced by morphology (saccular septal hyperplasia and reduced air sac formation) and decreased expression of epithelial differentiation markers. The invariable atelectasis is likely due to the failure in turning off cell proliferation, elevated cell cycle, and cell division signaling molecules. The present study, for the first time, reveals an indispensable physiological role of Dip2B in prenatal lung maturation and animal survival.

Neonatal respiratory distress syndrome (NRDS), often occurring in premature or low-weight infants, is associated with anatomical immaturity of the lung, increased compliance of chest wall, and inefficiency of premature pulmonary lymphatics coupled with decreased surfactant function or production [31-33]. Approximately 30\% of all neonatal deaths result from complications of NRDS. The development of respiratory distress with gasping, cyanosis, and low birth weight in Dip2 $b^{\text {tm1a/tm1a }}$ mice present a similar phenotype to the clinical manifestation of neonatal respiratory distress syndrome (NRDS). Given the decreased expression of Sfpta1, Sfptb and Sftpd, it is possible that Dip2b deletion might alter the activity of secreted surfactants, which is likely associated with respiratory failure at birth. Our findings may advance the knowledge of the underlying molecular mechanism of NRDS.

Prenatal lung maturation proceeds through a series of morphologically and biochemically defined stages [34,35]: from budding (E9.5) to initial development of bronchial and respiratory tree with the formation of an undifferentiated primordial system (Pseudoglandular from E9.5 to 16.6), to development of terminal sacs and vascularization (canalicular from E16.5 to 17.4), to increment in the number of terminal sacs and vascularization along with type I and II cells differentiation (Sacculation from E17.5 to P5). The final maturation of the terminal sacs into alveolar ducts and sacs (Alveolization) occurs postnatally from approximately P5 to P30 [36,37]. Dip2b mice form the correct number of lung lobes, together with the fact that all the Dip $2 b$ knockout mice survive embryogenesis, suggesting that Dip $2 b$ might not be a master gene that regulates the early stage of lung development. Instead, Dip $2 b$ might play a more important role during the mid-to-late stages of lung development. Our further evidence confirms that lung pathology induced in Dip $2 b$ mice is due to a delay in fetal pulmonary maturation rather than early-branching morphogenesis. Although we evidenced a delay in branching morphogenesis manifested at the early psuedoglandular stage (E11.5-E13.5), the overall growth of epithelial buds was comparatively comparable to wild type at the late psuedoglandular stage (E15.5). An increase in cell proliferation and cell apoptosis is involved in peripheral mesenchymal during normal branching morphogenesis [38]. The observation of a comparable number of BrdU positive cells between Dip $2 b$ and wild type lung at E15.5 supports the normal branching process. Nevertheless, Starting from E17.5 (the saccular stage), an obvious defect in alveolar maturation was seen in mutant lungs, as evident by a lack of saccules formation and thick interstitium septae although being grossly normal in architecture, collagen deposition, and intact pulmonary vessel development. Since the morbidity and mortality of premature infants are strongly associated with a failure of lung 
maturation [39], these mice may provide a useful model to investigate the later stages of prenatal lung maturation.

Our analysis showed that there is an apparent increase in the amount of DNA of Dip2 $b^{\text {tm1a/tm1a }}$ lungs, suggesting disturbed cell proliferation and/or apoptosis during lung maturation. Increased number of proliferating cells in Dip2 $b^{\text {tm1a/tm1a }}$ versus wild type as measured by BrdU staining and comparable cell death between wild type and mutant detected by TUNEL staining at E18.5 validated the outcome of a net increase of DNA content in mutants. Besides, these findings also indicate that the interstitium thickening of septae is the result of uncontrolled cell proliferation and not because of the failure of apoptosis. Previous studies of corticotropin-releasing hormone $(\mathrm{CRH})$ and glucocorticoid (GR) knockout mice have shown similar findings in which hypercellularity, failure of septal thinning and immature airway formation were seen with an abnormally prolonged period of lung proliferation rather than the failure of timely apoptosis $[40,41]$.

Lung maturation defect at late stages of fetal development has been seen in mice containing targeted disruption of genes encoding transforming growth factor [42], glucocorticoid receptor [39] neural precursor cell-expressed developmentally down-regulated 4 (NEDD4) [43], latent transforming growth factor $\beta$ binding proteins [44], and other genes [45-48]. The molecular mechanism linking this diverse set of molecules to the development events essential for lung maturation has not yet been determined. As for the underlying molecular mechanism for the observed defects in our study, the RNA-sequencing-based gene expression analysis showed that the expression of over 1400 genes was affected by the loss of Dip $2 b$ in E18.5 lung, indicating that many factors including ECM and growth factors are likely responsible for the lung phenotype of Dip $2 b^{\text {tm1a/tm1a }}$. Given the increased cell proliferation in Dip2 $b^{\text {tm1a/tm1a }}$ lungs, it is possible that upregulation of several genes annotated to biological processes such as cell proliferation, cell cycle, and cell division, results in the maturation arrest. Thus, Dip $2 b$ may be involved in either mesenchymal or epithelial cell exit from the cell proliferation, cell cycle, and cell division essential for normal maturation of the lung. As this is the first report on Dip2 $b^{\text {tm1a/tm1a }}$, further studies are still needed to validate this hypothesis. Future studies will also be needed to characterize the underlying mechanism of Dip2B in regulating biological process immune response and pathway oxidative phosphorylation.

During the alveogenesis process, epithelial progenitor cells differentiate into alveolar type 1 (AT1) and alveolar type 2 (AT2) cells [27]. The RNA-sequencing analysis and qPCR validation showed that structural immaturation of Dip2 $b^{\text {tm1a/tm1a }}$ lung was accompanied by the decreased mRNA level of several AT1 and AT2 differentiation markers, indicating impaired epithelial cell differentiation. The notable reductions of these markers caused by Dip $2 b$ deletion at the protein level remain to be elucidated. Also, it will be important to determine the effect of the declining level of AT cell transcripts on cell maturation. However, our model is in agreement with many genetically immature lung phenotypes, such as Rcn3 [49] and Fstl [50], in which increased cell proliferation in the saccular septa is accompanied by inhibition of epithelial cell differentiation due to reduced AT1 and AT2 marker expression.

In the present study, we provide evidence that Dip $2 b$ may modulate the G2/M phase transition pathway. Our RNA-sequencing analysis showed that Dip $2 b$ deletion resulted in an upregulation of the Ccnb1 gene, which is a regulatory subunit of mitosis promoting factor (MPF) needed for mitotic progression [51-53]. Cyclin B along with $C d c 2$ activation promotes M-phase entry in the cell cycle. Several factors regulate $C c n b: C d c 2$ complex, which include $C d k 1$ inhibitor $C d k n 1 a$ [54]. Similarly, $C d c 25 C$ is one of three $C d c 25$ isoforms present in mammalian cells and, in combination with $C d c 25 B$, promotes activation of MPF [54]. Drosophila polo kinase and its orthologues in other eukaryotes are also important regulators of G2/M transit, mitotic progression, cytokinesis, and exit from mitosis [55,56]. We hypothesize that downregulation in mRNA expression of Cdkn1a along with the upregulation of $C d c 25 c$ and Polo1 may contribute to the ultimate activation of MPF and further promote $\mathrm{M}$ phase entry during the cell cycle. However, the ultimate function and mechanism of Dip2B in the G2/M phase transition require further exploration. 
In summary, we provide evidence of an important role of Dip2B in late lung development. Insertion of Tm1a in the Dip $2 b$ allele allows us to study expression patterns of Dip2B expression and functional roles of Dip2B under inactivation. Knockout of Dip2B results in an intrauterine growth restriction and neonatal death possibly due to respiratory insufficiency. Delayed lung maturation includes increased lung tissue cellularity through cell proliferation, immature alveolar sacculation, and reduced alveolar septation. A decrease in mRNA levels for surfactant proteins and type I and type II epithelial cell markers provide the basis for the delayed maturation. In particular, gene expression profiling studies enabled us to demonstrate that Dip2B plays a novel role in the cell cycle, cell division, and G2/M phase transition. Results indicate that Dip2B is essential for lung development and survival.

\section{Materials and Methods}

\subsection{Animals}

Dip $2 b$ deficient (Dip2 $b^{t m 1 a(K O M P) W t s i}$, abbreviated to Dip2 $b^{t m 1 a}$ in this report) mice were purchased from KOMP (Mouse Gene Knockout Project). All animal experiments were conducted according to the guideline of the Institutional Animal Care and Use Committee, and Ethics Committee of Northeast Normal University (NENU/IACUC, 1 January 2018, AP2018011). Mice were housed in IVC cages in a clean facility of NENU under a 12:12 h light: dark cycles, $20^{\circ} \mathrm{C}$ and $50 \pm 20 \%$ humidity. Genotyping was performed by PCR and using two sets of primer: Tm1a-F (TGAGACTGAGCTTGGCTACCACA) and Tm1a-R (TCCTCCTACATAGTT GGCAGTGT), and WT-F (AGTTAAGGCTGAGCATGGTGGGA) and WT-R (TAGGGCTCTCACAGATCAGAGCT. Genomic DNA was extracted from tail tips by Proteinase K (Sigma) digestion [21]. Homozygotes Dip2 $b^{\text {tm1a/tm1a }}$ offspring were generated by intercrossing of heterozygotes (Dip2 $b^{t m 1 a /+}$ ) on C57Bl/6 genetic background.

\subsection{LacZ Staining}

Visualization of beta-galactosidase (LacZ) expression was done in whole mount embryos or organs dissected from Dip $2 b^{t m 1 a /+}$ pregnant dams. For whole mount staining, embryos from E9.5, E11.5 and E12.5 were harvested in ice-cold $1 \times$ PBS and fixed for $30 \mathrm{~min}$ in $2 \%$ PFA, $0.25 \%$ glutaraldehyde and $0.01 \%$ NP40 in PBS. Embryos were then washed three times, 15 min each in $2 \mathrm{mM} \mathrm{MgCl} 2$, $0.02 \% \mathrm{NP} 40$ and $0.01 \%$ Na-deoxycholate in PBS, and then incubated at $37^{\circ} \mathrm{C}$ overnight in $50-100 \mathrm{~mL}$ of an X-gal staining solution containing $30 \mathrm{mM} \mathrm{K}_{3} \mathrm{Fe}(\mathrm{CN})_{6}, 30 \mathrm{mM} \mathrm{K}_{4} \mathrm{Fe}(\mathrm{CN})_{6} \cdot 3 \mathrm{H}_{2} \mathrm{O}, 2 \mathrm{mM} \mathrm{MgCl}{ }_{2}$, $0.01 \%$ Na-deoxycholate, $0.02 \% \mathrm{NP} 40$, and $1 \mathrm{mg} / \mathrm{mL} 5$-bromo-4-chloro-3-indolyl- $\beta$-D-galactopyranoside in PBS (pH 7.5). Embryos were post-fixed in $4 \%$ PFA overnight and stored in $70 \%$ ethanol at $4{ }^{\circ} \mathrm{C}$. For frozen section staining, whole embryo and organs from E15.5 and E18.5 were dissected, fixed and washed as above. Samples were incubated in $20 \%$ sucrose overnight at $4{ }^{\circ} \mathrm{C}$ and then embedded in OCT compound (Tissue-Tek, Torrance, CA, USA) on dry ice. Sections were cut at $16 \mu \mathrm{m}$ thickness and mounted on SuperfrostTM Plus microscope slides and allowed to dry for $30 \mathrm{~min}$ at room temperature, and staining was performed as above. Sections were post-fixed and counterstained (only E15.5) with $0.25 \%$ eosin solution. Wild type mice were used as a negative control. Images of whole mount embryos and frozen section tissues were taken using Olympus light microscope (SXL-ILLB-200, Tokyo, Japan) and Canon digital camera (DSI26431, Tokyo, Japan).

\subsection{Cesarean Delivery and Weight Measurements}

Timed mating was set up by crossing heterozygous Dip $2 b^{\text {tm1a/+ }}$ females with Dip $2 b^{\text {tm1a/+ }}$ males. Female mice were checked for copulation plugs and designated as embryonic development day E0.5 of gestation. All females were separated and housed individually after a vaginal plug was identified. Pregnant females were sacrificed at different stages of gestation, and embryos were harvested by cesarean section. Each embryo was weighed and immersed in 1× PBS and further subjected to morphological study. Embryos were then dissected under a stereomicroscope (Olympus SZX7, Tokyo, 
Japan). Whole embryos and individual organs were weighed using an analytical balance (Shenyang Longteng Electronics Co., Ltd. ESJ182, Shenyang, China).

\subsection{Hydrostatic Lung Test}

A non-recovery cesarean section of Dip $2 b^{\text {tm1a/+ }}$ intercrossed female dams was performed at E19.5 (6-8 h before birth). Embryos were collected and placed on a $37^{\circ} \mathrm{C}$ heat pad and observed. After $60 \mathrm{~min}$ of observation, embryos were decapitated, and lung with trachea attached was placed into PBS and observed for floatation.

\subsection{Weight Measurement of Lungs}

The embryonic day (E) 18.5 lungs were removed from the chest cavity en bloc, dried with blotting paper and weighed to obtain wet lung weight. Lungs were then placed in a $60^{\circ} \mathrm{C}$ oven overnight to obtain dry weight.

\subsection{Lung Histology/Staining}

E15.5 and E17.5 embryos were dissected from the uterus and fixed in $4 \%$ PFA for $24 \mathrm{~h}$ at $4{ }^{\circ} \mathrm{C}$. The lungs from E18.5 embryos and P0 neonates were fixed for $24 \mathrm{~h}$ in $4 \%$ PFA at $4{ }^{\circ} \mathrm{C}$. The fixed tissues were then washed twice in $1 \mathrm{X}$ PBS and stored in $70 \%$ ethanol at $4{ }^{\circ} \mathrm{C}$. Briefly, tissues were dehydrated through a series of graded alcohols, cleared in xylene, infiltrated, and embedded in paraffin. Samples were taken from all five lobes. Six- $\mu$ m-thick sections were stained with H\&E. For Sirius red staining, paraffin section were hydrated and stained in sirius red solution (Sigma, Changchun, China) as instructed. Images were taken using Leica DMi8 light microscope (Leica Microsystem, Shanghai, China).

\subsection{Analysis of Lung Branching Morphogenesis}

Pregnant Dip2b ${ }^{\text {tm1a/+ }}$ mice were sacrificed at E11.5, E12.5, E13.5, and E15.5 stages, and embryonic lung was dissected. Whole mount lungs from E11.5-E13.5 and paraffin-embedded lungs section from E15.5 were examined to verify the quantification of terminal branching. Branching morphogenesis was expressed as the number of epithelial buds visible around lung peripheries, $n=3$.

\subsection{Quantification of Lung Alveolar Sac Formation}

Lung alveolar sac formation analysis was performed on H\&E-stained sections at E18.5 and P0. The number of terminal respiratory air sacs was calculated using Adobe Photoshop 6.0 software. Multiple measurements were performed on randomly selected $66.2 \mathrm{~m}$ fields located at the distal part of the lung sections. The method for quantification of alveolar wall thickness was previously described [57]. The areas for distal airways were measured by using the area measurement function in ImageJ and calculated for mean value and SD. For each sample, three pictures were taken under a 40X objective lens. Three pubs from each group were analyzed.

\subsection{5-Bromo-2-Deoxy-Uridine (BrdU) Labeling}

Pregnant dams at E15.5 and E18.5 were injected intraperitoneally (120 $\mu \mathrm{g} /$ gram body weight) with BrdU solution (Sigma Cat\#B5002). Two hours later, mice were sacrificed and embryos were harvested. Lungs from all embryos were removed and embedded in OCT, sectioned in cryostat microtome, and processed for immunohistochemical evaluation [24]. BrdU was revealed using the Anti-BrdU antibody (Rat monoclonal, Abcam Cat\#ab6326) for $1.5 \mathrm{~h}$ at room temperature. Slides were counterstained with DAPI (Invitrogen, Cat\#3571). Images were taken using DMi8 S platform live cell microscope (Leica Microsystem, China). Slides were scored by counting BrdU-labeled cells under microscopic fields (20X), $n=3$ for E15.5, $n=4$ for E18.5. 


\subsection{TUNEL Assay}

Apoptosis was detected and quantified in E18.5 lung paraffin sections using In Situ Cell Death Detection kit (Roche, Beijing, China) following the manufacturer's guideline [44]. Briefly, sections were treated in xylene and dehydrated in a series of graded alcohol and finally rinsed in $1 \times$ PBS. Sections were treated with proteinase $\mathrm{K}$ before adding tunnel reaction mixture. Slides were counterstained with DAPI, and images were taken under DMi8 S platform live cell microscope (Leica Microsystem, Shanghai, China). Ten fields for each slide were photographed and TUNEL-positive cells were counted.

\subsection{RNA-Sequencing (RNA-Seq)}

RNA-seq of E18.5 lungs was carried out as described before (Sah et al., 2019) using Illumina HiseqTM 2500 (Biomarker, Beijing, China). A total of three pairs of RNA samples (3 WT and 3 Dip $2 b^{t m 1 a / t m 1 a}$ ) were sequenced. Bioinformatics analyses were performed using GOseq R packages [58], Kobas [59] and DAVID software version 6.8. Sequence reads from RNA Sequencing generated in this study are deposited in the NCBI SRA database.

\subsection{Quantitative Real Time PCR (qPCR) Validation of RNA-Seq Results}

Total RNA $(1 \mu \mathrm{g})$ from E18.5 lungs of WT and Dip2 $b^{t m 1 a / t m 1 a}$ was subjected to cDNA synthesis in a $20 \mathrm{uL}$ reaction using primescriptTMII cDNA synthesis kit (Takara, Dalian, China). All qPCRs were performed using Thermocycler (Analytik Jena AG, Jena, Germany) and SYBR II premix (Takara, Dalian, China). All results were normalized to housekeeping gene 18S ribosomal RNA and relative quantification was calculated using comparative threshold cycle $\left(2^{-\Delta \Delta \mathrm{Ct}}\right)$ values for three biological replicates.

\subsection{Statistical Analysis}

The data are expressed as the SEM \pm SD. Statistical analyses were assessed using unpaired $t$-test, with statistical significance $p<0.05 . \chi 2$ analysis was done using the online calculation chi-square tool at http://www.quantpsy.org.

\subsection{Database}

\section{NCBI (SRA: PRJNA647345, https://www.ncbi.nlm.nih.gov/sra/PRJNA647345)5.}

Supplementary Materials: Supplementary Materials can be found at http:/www.mdpi.com/1422-0067/21/21/ 8223/s1. VideoS1. Respiratory Distress among Dip2 $b^{t m 1 a / t m 1 a}$ mice soon after birth. Figure S1. Picro-sirius red stained sections of lung at E18.5. Figure S2. Cell apoptosis assay by TUNEL staining. A. Immunofluorescent TUNEL staining of E18.5 lungs. Scale bar: $66.2 \mu \mathrm{m}$. B. Quantitative analysis by counting of multiple sections from 3 independent samples per group. NS = not significant by student's $t$-test. Table S1. Summary of RNA-Seq mapping results. The raw reads were mapped to the Mus Musculus genome (GRCm38) using TopHat2. Table S2. List of DEG (Differentially Expressed Gene) from RNA-Seq analysis results. Differentail expression analysis was carried out using DESeq2. Table S3. List of DEGs annotated under Gene Ontology (GO) terms cell cycle and immune system process. Table S4. List of DEGs annotated under KEGG Pathway oxidative phosphorylation and hematopoietic cell lineage pathways.

Author Contributions: Conceptualization, L.Z., R.K.S. and Y.Z.; methodology, R.K.S., J.M. and S.A.; software, R.K.S., Y.W. and F.H.N.; validation, R.K.S. and Y.Z.; formal analysis, R.K.S., F.B.B., S.A. and Z.X.; investigation, R.K.S., Z.M.O., N.B., S.A. and A.A.B.; resources, Z.X., Y.W. and Y.Z.; data curation, R.K.S., F.B.B., N.B., Z.M.O. and F.H.N.; writing-original draft preparation, R.K.S.; writing-review and editing, Y.Z. and L.Z.; visualization, J.M. and A.A.B.; supervision, Y.Z.; project administration, Y.Z. and X.F.; funding acquisition, X.F., L.Z. and Y.Z. All authors have read and agreed to the published version of the manuscript.

Funding: This research was funded by National Natural Science Foundation of China, grant number 31301189 and 81270953 and Natural Science Foundation of Jilin Province, grant number 20200201127JC and 20160101344JC.

Acknowledgments: We would like to thank Huiyan Wu and Xiulu Lv for mouse colony management and Xiao Juan Zhu for providing reagents. 
Conflicts of Interest: The authors declare no conflict of interest. The funders had no role in the design of the study; in the collection, analyses, or interpretation of data; in the writing of the manuscript, or in the decision to publish the results.

\section{Abbreviations}

Dip2a Disco Interacting protein 2 Homolog a

Dip $2 b \quad$ Disco Interacting protein 2 Homolog $b$

Dip2c Disco Interacting protein 2 Homolog c

LacZ $\beta$-Galactosidase

BrdU 5-Bromo-2-Deoxy-Uridine

GO Gene Ontology

KEGG Kyoto Encyclopedia of Genes and Genomes

\section{References}

1. Tanaka, M.; Murakami, K.; Ozaki, S.; Imura, Y.; Tong, X.-P.; Watanabe, T.; Sawaki, T.; Kawanami, T.; Kawabata, D.; Fujii, T.; et al. DIP2 disco-interacting protein 2 homolog A (Drosophila) is a candidate receptor for follistatin-related protein/follistatin-like 1-Analysis of their binding with TGF- $\beta$ superfamily proteins. FEBS J. 2010, 277, 4278-4289. [CrossRef] [PubMed]

2. Mukhopadhyay, M.; Pelka, P.; DeSousa, D.; Kablar, B.; Schindler, A.; Rudnicki, M.A.; Campos, A.R. Cloning, genomic organization and expression pattern of a novel Drosophila gene, the disco-interacting protein 2 (dip2), and its murine homolog. Gene 2002, 293, 59-65. [CrossRef]

3. Nitta, Y.; Yamazaki, D.; Sugie, A.; Hiroi, M.; Tabata, T. DISCO Interacting Protein 2 regulates axonal bifurcation and guidance of Drosophila mushroom body neurons. Dev. Biol. 2017, 421, 233-244. [CrossRef] [PubMed]

4. Nitta, Y.; Sugie, A. DISCO interacting protein 2 determines direction of axon projection under the regulation of c-Jun N-terminal kinase in the Drosophila mushroom body. Biochem. Biophys. Res. Commun. 2017, 487, 116-121. [CrossRef] [PubMed]

5. Noblett, N.; Wu, Z.; Ding, Z.H.; Park, S.; Roenspies, T.; Flibotte, S.; Chisholm, A.D.; Jin, Y.; Colavita, A. DIP-2 suppresses ectopic neurite sprouting and axonal regeneration in mature neurons. J. Cell Biol. 2019, 218, 125-133. [CrossRef] [PubMed]

6. Ouchi, N.; Asaumi, Y.; Ohashi, K.; Higuchi, A.; Sono-Romanelli, S.; Oshima, Y.; Walsh, K. DIP2A functions as a FSTL1 receptor. J. Biol. Chem. 2010, 285, 7127-7134. [CrossRef]

7. Liang, X.; Hu, Q.; Li, B.; McBride, D.; Bian, H.; Spagnoli, P.; Chen, D.; Tang, J.; Zhang, J.H. Follistatin-like 1 attenuates apoptosis via disco-interacting protein 2 homolog A/Akt pathway after middle cerebral artery occlusion in rats. Stroke 2014, 45, 3048-3054. [CrossRef] [PubMed]

8. Nie, E.; Miao, F.; Jin, X.; Wu, W.; Zhou, X.; Zeng, A.; Yu, T.; Zhi, T.; Shi, Z.; Wang, Y.; et al. Fstl1/DIP2A/MGMT signaling pathway plays important roles in temozolomide resistance in glioblastoma. Oncogene 2019, 38, 2706-2721. [CrossRef] [PubMed]

9. Kudo-Saito, C.; Ishida, A.; Shouya, Y.; Teramoto, K.; Igarashi, T.; Kon, R.; Saito, K.; Awada, C.; Ogiwara, Y.; Toyoura, M. Blocking the FSTL1-DIP2A Axis Improves Anti-tumor Immunity. Cell Rep. 2018, 24, 1790-1801. [CrossRef]

10. Ma, J.; Zhang, L.-Q.; He, Z.-X.; He, X.-X.; Wang, Y.-J.; Jian, Y.-L.; Wang, X.; Zhang, B.-B.; Su, C.; Lu, J.; et al. Autism candidate gene DIP2A regulates spine morphogenesis via acetylation of cortactin. PLoS Biol. 2019, 17, e3000461. [CrossRef]

11. Egger, G.; Roetzer, K.M.; Noor, A.; Lionel, A.C.; Mahmood, H.; Schwarzbraun, T.; Boright, O.; Mikhailov, A.; Marshall, C.R.; Windpassinger, C.; et al. Identification of risk genes for autism spectrum disorder through copy number variation analysis in Austrian families. Neurogenetics 2014, 15, 117-127. [CrossRef] [PubMed]

12. Poelmans, G.; Engelen, J.J.M.; Van Lent-Albrechts, J.; Smeets, H.J.; Schoenmakers, E.; Franke, B.; Buitelaar, J.K.; Wuisman-Frerker, M.; Erens, W.; Steyaert, J.; et al. Identification of novel dyslexia candidate genes through the analysis of a chromosomal deletion. Am. J. Med. Genet. Part B Neuropsychiatr. Genet. Off. Publ. Int. Soc. Psychiatr. Genet. 2009, 150B, 140-147. [CrossRef] [PubMed] 
13. DeScipio, C.; Conlin, L.; Rosenfeld, J.; Tepperberg, J.; Pasion, R.; Patel, A.; McDonald, M.T.; Aradhya, S.; Ho, D.; Goldstein, J.; et al. Subtelomeric deletion of chromosome 10p15.3: Clinical findings and molecular cytogenetic characterization. Am. J. Med. Genet. A 2012, 158A, 2152-2161. [CrossRef]

14. Larsson, C.; Ali, M.A.; Pandzic, T.; Lindroth, A.M.; He, L.; Sjöblom, T. Loss of DIP2C in RKO cells stimulates changes in DNA methylation and epithelial-mesenchymal transition. BMC Cancer 2017, 17, 487. [CrossRef]

15. Winnepenninckx, B.; Debacker, K.; Ramsay, J.; Smeets, D.; Smits, A.; FitzPatrick, D.R.; Kooy, R.F. CGG-repeat expansion in the DIP2B gene is associated with the fragile site FRA12A on chromosome 12q13.1. Am. J. Hum. Genet. 2007, 80, 221-231. [CrossRef] [PubMed]

16. Hayashi, T.; Lombaert, I.M.A.; Hauser, B.R.; Patel, V.N.; Hoffman, M.P. Exosomal MicroRNA Transport from Salivary Mesenchyme Regulates Epithelial Progenitor Expansion during Organogenesis. Dev. Cell 2017, 40, 95-103. [CrossRef]

17. Zhao, Y.; He, A.; Zhu, F.; Ding, M.; Hao, J.; Fan, Q.; Li, P.; Liu, L.; Du, Y.; Liang, X.; et al. Integrating genome-wide association study and expression quantitative trait locus study identifies multiple genes and gene sets associated with schizophrenia. Prog. Neuro-Psychopharmacol. Biol. Psychiatry 2018, 81, 50-54. [CrossRef]

18. Gong, J.; Qiu, C.; Huang, D.; Zhang, Y.; Yu, S.; Zeng, C. Integrative functional analysis of super enhancer SNPs for coronary artery disease. J. Hum. Genet. 2018, 63, 627-638. [CrossRef]

19. Zhou, J.; Liu, X.; Wang, C.; Li, C. The correlation analysis of miRNAs and target genes in metastasis of cervical squamous cell carcinoma. Epigenomics 2018, 10, 259-275. [CrossRef]

20. Closa, A.; Cordero, D.; Sanz-Pamplona, R.; Solé, X.; Crous-Bou, M.; Paré-Brunet, L.; Berenguer, A.; Guino, E.; Lopez-Doriga, A.; Guardiola, J.; et al. Identification of candidate susceptibility genes for colorectal cancer through eQTL analysis. Carcinogenesis 2014, 35, 2039-2046. [CrossRef]

21. Zhang, L.; Jia, R.; Palange, N.J.; Satheka, A.C.; Togo, J.; An, Y.; Humphrey, M.; Ban, L.; Ji, Y.; Jin, H.; et al. Large genomic fragment deletions and insertions in mouse using CRISPR/Cas9. PLoS ONE 2015, 10, e0120396. [CrossRef] [PubMed]

22. Zhang, L.; Mabwi, H.A.; Palange, N.J.; Jia, R.; Ma, J.; Bah, F.B.; Sah, R.K.; Li, D.; Wang, D.; Bah, F.B.M.; et al. Expression Patterns and Potential Biological Roles of Dip2a. PLoS ONE 2015, 10, e0143284. [CrossRef]

23. Ma, J.; Chen, L.; He, X.X.; Wang, Y.J.; Yu, H.L.; He, Z.X.; Zhang, L.Q.; Zheng, Y.W.; Zhu, X.J. Functional prediction and characterization of Dip2 gene in mice. Cell Biol. Int. 2019, 43, 421-428. [CrossRef] [PubMed]

24. Sah, R.K.; Yang, A.; Bah, F.B.; Adlat, S.; Bohio, A.A.; Oo, Z.M.; Wang, C.; Myint, M.Z.Z.; Bahadar, N.; Zhang, L.; et al. Correction: Transcriptome profiling of mouse brain and lung under Dip2a regulation using RNA-sequencing. PLoS ONE 2019, 14, e0225570. [CrossRef]

25. Skarnes, W.C.; Rosen, B.; West, A.P.; Koutsourakis, M.; Bushell, W.; Iyer, V.; Mujica, A.O.; Thomas, M.; Harrow, J.; Cox, T.; et al. A conditional knockout resource for the genome-wide study of mouse gene function. Nature 2011, 474, 337-344. [CrossRef]

26. Stiles, A.D.; Chrysis, D.; Jarvis, H.W.; Brighton, B.; Moats-Staats, B.M. Programmed cell death in normal fetal rat lung development. Exp. Lung Res. 2001, 27, 569-587. [CrossRef]

27. Warburton, D.; El-Hashash, A.; Carraro, G.; Tiozzo, C.; Sala, F.; Rogers, O.; De Langhe, S.; Kemp, P.J.; Riccardi, D.; Torday, J.; et al. Lung organogenesis. Curr. Top. Dev. Biol. 2010, 90, 73-158. [CrossRef] [PubMed]

28. Treutlein, B.; Brownfield, D.G.; Wu, A.R.; Neff, N.F.; Mantalas, G.L.; Espinoza, F.H.; Desai, T.J.; Krasnow, M.A.; Quake, S.R. Reconstructing lineage hierarchies of the distal lung epithelium using single-cell RNA-seq. Nature 2014, 509, 371-375. [CrossRef]

29. Zhou, Y.; Horowitz, J.C.; Naba, A.; Ambalavanan, N.; Atabai, K.; Balestrini, J.; Bitterman, P.B.; Corley, R.A.; Ding, B.-S.; Engler, A.J.; et al. Extracellular matrix in lung development, homeostasis and disease. Matrix Biol. 2018, 73, 77-104. [CrossRef] [PubMed]

30. Desai, T.J.; Cardoso, W.V. Growth factors in lung development and disease: Friends or foe? Respir. Res. 2001, 3, 2. [CrossRef]

31. Speer, C.P. Neonatal respiratory distress syndrome: An inflammatory disease? Neonatology 2011, 99, 316-319. [CrossRef]

32. Morrisey, E.E.; Hogan, B.L.M. Preparing for the first breath: Genetic and cellular mechanisms in lung development. Dev. Cell 2010, 18, 8-23. [CrossRef]

33. Whitsett, J.A.; Weaver, T.E. Alveolar development and disease. Am. J. Respir. Cell Mol. Biol. 2015, 53, 1-7. [CrossRef] [PubMed] 
34. Herriges, M.; Morrisey, E.E. Lung development: Orchestrating the generation and regeneration of a complex organ. Development 2014, 141, 502-513. [CrossRef] [PubMed]

35. Costa, R.H.; Kalinichenko, V.V.; Lim, L. Transcription factors in mouse lung development and function. Am. J. Physiol. Lung Cell. Mol. Physiol. 2001, 280, L823-L838. [CrossRef] [PubMed]

36. Prodhan, P.; Kinane, T.B. Developmental paradigms in terminal lung development. Bioessays 2002, 24, 1052-1059. [CrossRef]

37. Warburton, D.; Schwarz, M.; Tefft, D.; Flores-Delgado, G.; Anderson, K.D.; Cardoso, W.V. The molecular basis of lung morphogenesis. Mech. Dev. 2000, 92, 55-81. [CrossRef]

38. Carraro, G.; del Moral, P.-M.; Warburton, D. Mouse embryonic lung culture, a system to evaluate the molecular mechanisms of branching. J. Vis. Exp. 2010. [CrossRef]

39. Effect of corticosteroids for fetal maturation on perinatal outcomes. NIH Consens. Statement 1994, 12, 1-24.

40. Muglia, L.J.; Bae, D.S.; Brown, T.T.; Vogt, S.K.; Alvarez, J.G.; Sunday, M.E.; Majzoub, J.A. Proliferation and differentiation defects during lung development in corticotropin-releasing hormone-deficient mice. Am. J. Respir. Cell Mol. Biol. 1999, 20, 181-188. [CrossRef]

41. Bird, A.D.; Tan, K.H.; Olsson, P.F.; Zieba, M.; Flecknoe, S.J.; Liddicoat, D.R.; Mollard, R.; Hooper, S.B.; Cole, T.J. Identification of glucocorticoid-regulated genes that control cell proliferation during murine respiratory development. J. Physiol. 2007, 585, 187-201. [CrossRef] [PubMed]

42. Shi, W.; Heisterkamp, N.; Groffen, J.; Zhao, J.; Warburton, D.; Kaartinen, V. TGF-beta3-null mutation does not abrogate fetal lung maturation in vivo by glucocorticoids. Am. J. Physiol. 1999, 277, L1205-L1213. [CrossRef] [PubMed]

43. Rodriguez-Gil, J.L.; Watkins-Chow, D.E.; Baxter, L.L.; Yokoyama, T.; Zerfas, P.M.; Starost, M.F.; Gahl, W.A.; Malicdan, M.C.V.; Porter, F.D.; Platt, F.M.; et al. NPC1 Deficiency in Mice is Associated with Fetal Growth Restriction, Neonatal Lethality and Abnormal Lung Pathology. J. Clin. Med. 2019, 9, 12. [CrossRef]

44. Colarossi, C.; Chen, Y.; Obata, H.; Jurukovski, V.; Fontana, L.; Dabovic, B.; Rifkin, D.B. Lung alveolar septation defects in Ltbp-3-null mice. Am. J. Pathol. 2005, 167, 419-428. [CrossRef]

45. Steele-Perkins, G.; Plachez, C.; Butz, K.G.; Yang, G.; Bachurski, C.J.; Kinsman, S.L.; Litwack, E.D.; Richards, L.J.; Gronostajski, R.M. The transcription factor gene Nfib is essential for both lung maturation and brain development. Mol. Cell. Biol. 2005, 25, 685-698. [CrossRef]

46. Manwani, N.; Gagnon, S.; Post, M.; Joza, S.; Muglia, L.; Cornejo, S.; Kaplan, F.; Sweezey, N.B. Reduced viability of mice with lung epithelial-specific knockout of glucocorticoid receptor. Am. J. Respir. Cell Mol. Biol. 2010, 43, 599-606. [CrossRef]

47. Zhao, J.; Chen, H.; Peschon, J.J.; Shi, W.; Zhang, Y.; Frank, S.J.; Warburton, D. Pulmonary hypoplasia in mice lacking tumor necrosis factor-alpha converting enzyme indicates an indispensable role for cell surface protein shedding during embryonic lung branching morphogenesis. Dev. Biol. 2001, 232, 204-218. [CrossRef]

48. Boase, N.A.; Rychkov, G.Y.; Townley, S.L.; Dinudom, A.; Candi, E.; Voss, A.K.; Tsoutsman, T.; Semsarian, C.; Melino, G.; Koentgen, F.; et al. Respiratory distress and perinatal lethality in Nedd4-2-deficient mice. Nat. Commun. 2011, 2, 287. [CrossRef] [PubMed]

49. Jin, J.; Li, Y.; Ren, J.; Man Lam, S.; Zhang, Y.; Hou, Y.; Zhang, X.; Xu, R.; Shui, G.; Ma, R.Z. Neonatal Respiratory Failure with Retarded Perinatal Lung Maturation in Mice Caused by Reticulocalbin 3 Disruption. Am. J. Respir. Cell Mol. Biol. 2016, 54, 410-423. [CrossRef]

50. Geng, Y.; Dong, Y.; Yu, M.; Zhang, L.; Yan, X.; Sun, J.; Qiao, L.; Geng, H.; Nakajima, M.; Furuichi, T.; et al. Follistatin-like 1 (Fstl1) is a bone morphogenetic protein (BMP) 4 signaling antagonist in controlling mouse lung development. Proc. Natl. Acad. Sci. USA 2011, 108, 7058-7063. [CrossRef]

51. Gould, K.L. Cyclin-dependent protein kinases. In Protein Kinases; Woodgett, J.R., Ed.; IRL Press: Oxford, UK, 1994; pp. 149-176.

52. Lew, D.J.; Kornbluth, S. Regulatory roles of cyclin dependent kinase phosphorylation in cell cycle control. Curr. Opin. Cell Biol. 1996, 8, 795-804. [CrossRef]

53. Morgan, D.O. Principles of CDK regulation. Nature 1995, 374, 131-134. [CrossRef] [PubMed]

54. Ohi, R.; Gould, K.L. Regulating the onset of mitosis. Curr. Opin. Cell Biol. 1999, 11, 267-273. [CrossRef]

55. Nigg, E.A. Polo-like kinases: Positive regulators of cell division from start to finish. Curr. Opin. Cell Biol. 1998, 10, 776-783. [CrossRef]

56. Qian, Y.W.; Erikson, E.; Li, C.; Maller, J.L. Activated polo-like kinase Plx1 is required at multiple points during mitosis in Xenopus laevis. Mol. Cell. Biol. 1998, 18, 4262-4271. [CrossRef] [PubMed] 
57. Herriges, M.J.; Swarr, D.T.; Morley, M.P.; Rathi, K.S.; Peng, T.; Stewart, K.M.; Morrisey, E.E. Long noncoding RNAs are spatially correlated with transcription factors and regulate lung development. Genes Dev. 2014, 28, 1363-1379. [CrossRef]

58. Young, M.D.; Wakefield, M.J.; Smyth, G.K.; Oshlack, A. Gene ontology analysis for RNA-seq: Accounting for selection bias. Genome Biol. 2010, 11, R14. [CrossRef]

59. Wu, J.; Mao, X.; Cai, T.; Luo, J.; Wei, L. KOBAS server: A web-based platform for automated annotation and pathway identification. Nucleic Acids Res. 2006, 34, W720-W724. [CrossRef]

Publisher's Note: MDPI stays neutral with regard to jurisdictional claims in published maps and institutional affiliations.

(C) 2020 by the authors. Licensee MDPI, Basel, Switzerland. This article is an open access article distributed under the terms and conditions of the Creative Commons Attribution (CC BY) license (http://creativecommons.org/licenses/by/4.0/). 